\title{
English Learners' Sense of Progress in EFL and ESL Settings: A Qualitative Inquiry
}

by

\author{
Juliana Bahia
}

\begin{abstract}
A thesis submitted to the Faculty of Graduate Studies and Research in partial fulfillment of the requirements for the degree of Master of Arts
\end{abstract}
School of Linguistics and Applied Language Studies Carleton University Ottawa, Canada

December 2006

(a) 2006, Juliana Bahia 


$\begin{array}{ll}\begin{array}{l}\text { Library and } \\ \text { Archives Canada }\end{array} & \begin{array}{l}\text { Bibliothèque et } \\ \text { Archives Canada }\end{array} \\ \begin{array}{l}\text { Published Heritage } \\ \text { Branch }\end{array} & \begin{array}{l}\text { Direction du } \\ \text { Patrimoine de l'édition }\end{array} \\ \begin{array}{l}\text { 395 Wellington Street } \\ \text { Ottawa ON K1A ON4 }\end{array} & \begin{array}{l}\text { 395, rue Wellington } \\ \text { Ottawa ON K1A ON4 } \\ \text { Canada }\end{array}\end{array}$

Your file Votre référence ISBN: 978-0-494-23311-5 Our file Notre référence ISBN: 978-0-494-23311-5

NOTICE:

The author has granted a nonexclusive license allowing Library and Archives Canada to reproduce, publish, archive, preserve, conserve, communicate to the public by telecommunication or on the Internet, loan, distribute and sell theses worldwide, for commercial or noncommercial purposes, in microform, paper, electronic and/or any other formats.

The author retains copyright ownership and moral rights in this thesis. Neither the thesis nor substantial extracts from it may be printed or otherwise reproduced without the author's permission.
AVIS:

L'auteur a accordé une licence non exclusive permettant à la Bibliothèque et Archives Canada de reproduire, publier, archiver, sauvegarder, conserver, transmettre au public par télécommunication ou par l'Internet, prêter, distribuer et vendre des thèses partout dans le monde, à des fins commerciales ou autres, sur support microforme, papier, électronique et/ou autres formats.

L'auteur conserve la propriété du droit d'auteur et des droits moraux qui protège cette thèse. $\mathrm{Ni}$ la thèse ni des extraits substantiels de celle-ci ne doivent être imprimés ou autrement reproduits sans son autorisation.
In compliance with the Canadian

Privacy Act some supporting forms may have been removed from this thesis.

While these forms may be included in the document page count, their removal does not represent any loss of content from the thesis.
Conformément à la loi canadienne sur la protection de la vie privée, quelques formulaires secondaires ont été enlevés de cette thèse.

Bien que ces formulaires aient inclus dans la pagination, il n'y aura aucun contenu manquant.

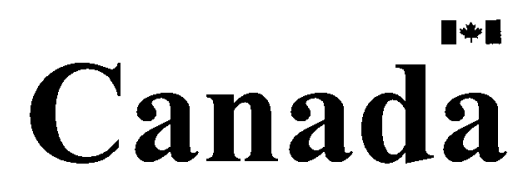




\begin{abstract}
This study addresses learners' sense of progress in learning English as a Foreign Language and as a Second Language. Sense of progress is a construct that, as of today, has not been extensively treated in the field of applied language studies. It seems to be intrinsically related to several aspects such as metacognition, motivation, individual definitions of successes and failures, attributions and goals. It is also apparent that sense of progress is a powerful motivational component, i.e. a positive sense of progress may contribute to higher levels of motivation to learn a language. This qualitative inquiry investigates the ways the aspects mentioned above operate in terms of perceptions and experiences of four Brazilian EFL learners and two Brazilian ESL learners. In addition, it presents two aspects that emerged from the data as relevant to this inquiry: language skills and language anxiety. The ways participants' individual perceptions on these aspects may contribute to foster or hinder a sense of progress are illustrated and discussed. It is argued that it is imperative for language teachers to develop a positive sense of progress in their learners.
\end{abstract}




\section{Acknowledgments}

First of all, I would like to thank my six participants for generously sharing their stories, perceptions, and opinions with me over the course of this study. I am also deeply grateful to my supervisor, Devon, for showing me the possibilities when things seemed impossible to achieve. Thank you also for your friendship, your parties and your love for Brazilian music and culture.

I would like to dedicate this work to my mother, Nely, who has always reminded me of my life goals, especially in critical moments. She was my inspiration to carry out and conclude this work. I would also like to thank all my brothers and sisters, nephews and nieces, who have always been on my side and in my thoughts since I left Brazil to study in Canada, especially Rosalva and Mara who have always been there for me under any circumstances with unconditional love. My deepest gratitude also goes to Márcio for his support and encouragement since I started the MA program. Many thanks to my dear friends in Ottawa who became my family in Canada. Thank you Sabrina and Fátima for listening, understanding, and trying to get me out of the house when I was stressed out over the thesis work. Thank you Lynnda, Maria and Moon for giving me the shelter, the comfort and the support I needed to complete this work under difficult life-changing circumstances. Finally, my special thanks goes to Daniel, who closely followed my final steps towards the completion of this work. Thank you for all the rides to the library, for bringing and connecting all the computer gadgets, and even for not leaving me alone when I needed to get work done. Above all, thank you for showing me what love is really about. 


\section{CONTENTS}

Chapter 1. Introduction ....................................................................... 1

Chapter 2. Towards a Theoretical Conceptualization of Sense of Progress in L2 Learning .. 4

Sense of Progress as Metacognitive Knowledge .................................. 6

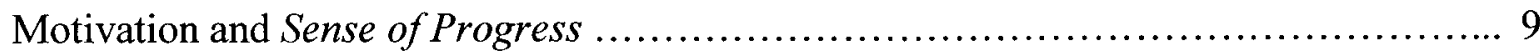

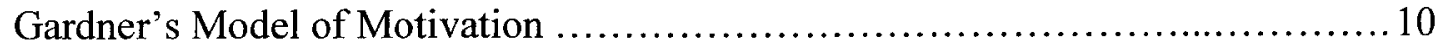

Williams \& Burden's Model of Motivation ................................ 12

Dörnyei's Model of Motivation ............................................ 15

Sense of Progress and Individuals' Definitions of Success and Failure .................18

Attribution Theory and Sense of Progress........................................20

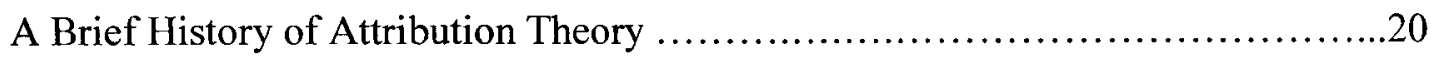

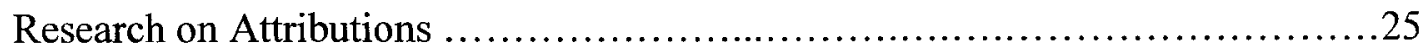

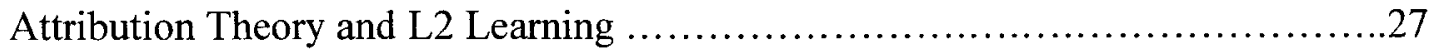

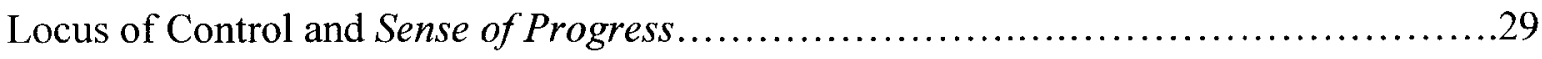

Learners' Goals and Sense of Progress......................................... 31

Summary - A Tentative Definition of Sense of Progress .............................34

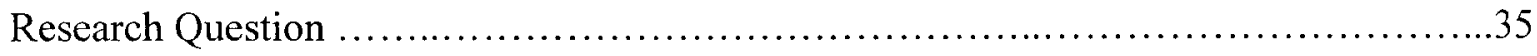

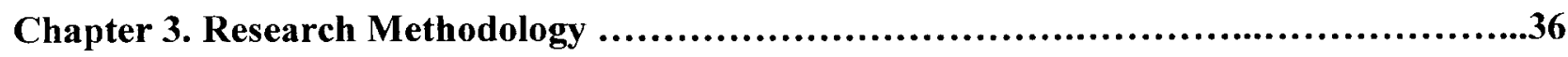

Methodological Issues in Research on Sense of Progress in L2 Learning................36 
Methodology in the Present Study .................................................. 40

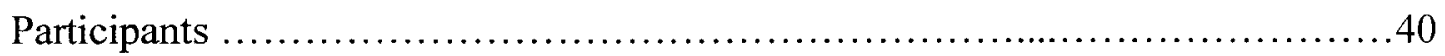

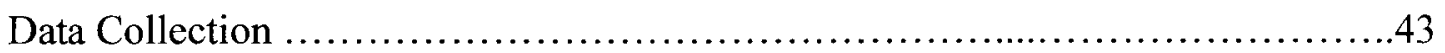

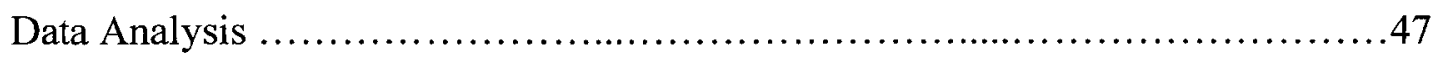

Methodological Limitations of Present Study .......................................51

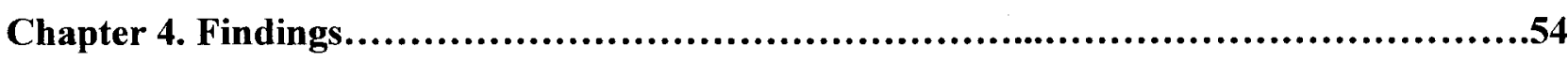

Participants' Sense of Progress Profiles...............................................55

Participants' Perceptions about Theoretical Aspects of Sense of Progress ..................60

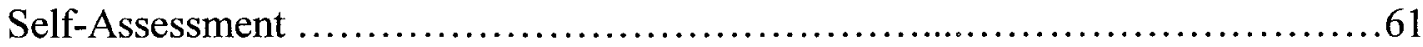

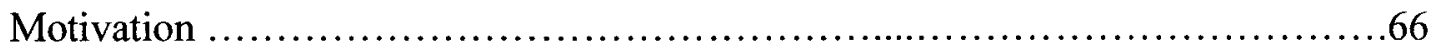

Definitions of Success and Failure .......................................... 73

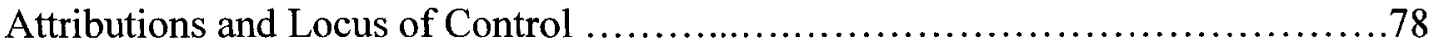

Learning Goals ........................................................ 90

Participants' Perceptions about Other Aspects Related to Sense of Progress ..............98

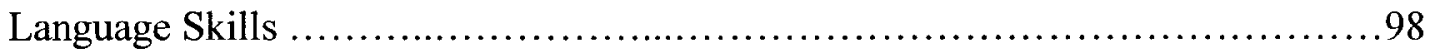

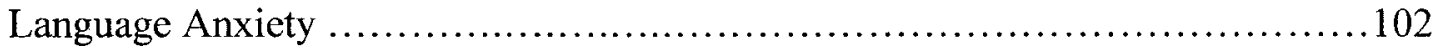

Revisiting the Definition of Sense of Progress ....................................107

Chapter 5. Implications and Conclusion ...................................................109 


\section{Chapter 1. Introduction}

$\mathrm{L} 2^{1}$ learner perceptions may comprise a multiplicity of aspects related to their learning experiences such as opinions about instructors, judgment on classroom activities and pedagogical approaches, and manifestations of satisfaction with their progress in language learning (Tse, 2000). The latter aspect - satisfaction with learning progress - is often acknowledged by practitioners in the field as a crucial motivational element that needs to be fostered in students. It is commonly assumed by L2 teachers that, if learners are not satisfied with their language learning accomplishments, their motivation to persist in the learning enterprise will be negatively affected. This assumption constitutes an alternative position to established language learning motivation models that claim that motivation is a priori factor to learning success (Beebe and Giles, 1984; Gardner and Lambert, 1959; Krashen, 1981, 1982, 1985; Mowrer, 1950). Other authors, however, have argued more recently that motivation is not only a cause of L2 learning success, but also a result of it (Crookes and Schmidt, 1991; Dörnyei, 1990, 1994, 1996, 2003). According to the latter perspective, there is a cyclical relationship between motivation and learning achievement - motivation may lead to learning success, which in turn, may result in further motivation to learn. The latter component of the circle is the so-called resultative hypothesis on motivation (Skehan, 1989), that regards motivation as a consequence rather than a cause of learning success.

Therefore, it is of paramount importance to examine not only how motivation may affect learning achievement, but also how learning achievement may bear an impact on motivation. In

I The acronym L2 refers to both FL (foreign language) and SL (second language) learning contexts. 
order to investigate the latter relationship, it is essential to scrutinize how learners perceive their learning successes, that is, what constitutes their sense of progress in language learning.

Notwithstanding its perceived motivational value, students' sense of progress in L2 language learning is a construct that - as of today - has received virtually no theoretical and empiric consideration in the field of second language acquisition. Such consideration might be useful in view of the fact that it could inform teachers who wish to develop a constructive and effective sense of progress in their learners. This development could be attained more successfully if teachers are able to develop a more profound and insightful understanding of the aspects the concept sense of progress might entail.

In order to develop an understanding of learners' development of a sense of progress, research needs to be conducted with the aim of determining how individuals interpret their learning experiences in ways that contribute to their perceptions of progress in L2 learning (Williams and Burden, 1997). This aim will be the main purpose of this study.

The body of this work consists of three major chapters. Chapter Two presents a theoretical analysis of constructs drawn from the fields of applied linguistics, education and psychology with the aim of constructing a tentative theoretical definition of sense of progress. This analysis and definition establishes the theoretical foundation for research question that is presented in the same chapter. Chapter Three presents a discussion of issues in research methodology, describes the research methodology adopted for the present study, and outlines the methodological limitations the researcher encountered while undertaking the study. In Chapter Four, the findings of the research conducted for the study are presented and analyzed in four sections. Section One presents sense of 
progress profiles of the six participants in this study. Section Two addresses the research question presented in Chapter Two. Section Three presents findings that are not directly related to the research question but were regarded as relevant since they consist of patterns that emerged repeatedly during the data analysis stage of the research. Section Four presents a reformulation of the tentative theoretical definition of sense of progress (introduced in Chapter Two) that includes new elements derived from the data analysis carried out for the study. 


\section{Chapter 2. Towards a Theoretical Conceptualization of the Construct Sense of Progress in L2 Learning}

A theoretical review will be undertaken in this chapter in an attempt to propose a conceptualization of the construct sense of progress in language learning. Following extensive research of relevant literature in the fields of applied linguistics, education and psychology, the researcher identified key aspects that might be relevant in this theoretical conceptualization. It is essential at this point to indicate the tentative nature of this theoretical speculation that will not make any definitive claims. The identification and analysis of the theoretical aspects represent only a first step towards a delineation of the construct. However, they function, as well, as a springboard for the research that was undertaken in the study.

It will be proposed in this chapter that sense of progress in language learning:

1. may be viewed as L2 learners' metacognitive knowledge (Cortazzi and Jin, 1996; Rivers, 2001; Wenden, 1991);

2. is a crucial component of the broader construct motivation in L2 learning (Dörnyei, 2005; Gardner, 1985; Gardner and Lambert, 1972; Gardner and Tremblay, 1995; Oxford and Shearin, 1994; Skehan, 1989; Williams and Burden, 1997);

3. is determined by individuals' definitions of successes and failures in L2 learning (Frieze et al, 1983; Williams and Burden, 1999);

4. is determined by attributions that individuals make for their perceived successes and failures in L2 learning (Dörnyei, 1990; Graham, 2004; Heider, 1958; Weiner, 1983, 1986); 
5. must be contemplated in face of L2 learners' goals (Bandura, 1997; Locke and Latham, 1984, 1994);

6. is fundamental in fostering in L2 learners a feeling of personal control over their learning (Findley and Cooper, 1983; Rotter, 1954).

It will be argued that the notion of L2 learners' sense of progress is directly linked to at least the six crucial aspects mentioned above. An overview of the theoretical developments related to each of these above aspects will be presented with the goal of proposing a tentative theoretical conceptualization of sense of progress in L2 learning.

Several claims have been made about the value of investigating the aspects mentioned above. A number of writers have called for the importance of integrating into motivation research the cognitive views of motivation prominent in the psychological literature (Crookes and Schmidt, 1991; Dörnyei, 1994; Oxford and Shearin, 1994; Williams and Burden, 1997). In this light, a variety of studies into cognitive dimensions of L2 learning motivation have been conducted and several arguments have been presented. Studies include investigations of a quantitative nature, e.g. Clement et al, 1994; Gardner and Tremblay, 1995; Ozek and Williams, 2000. Arguments in favor of research on the aspects enumerated above also include Williams and Burden's (1997) idea that locus of control and attribution theory are fields that could successfully be investigated in order to improve understanding of individuals (Williams and Burden, 1997), and Skehan's (1989) observation that "it would be desirable if more attribution theory research were carried out in the language learning field given that such research might synthesize many of the individual differences into a more coherent account of language learning" (Skehan, 1989, p. 52). Tse (2000) also draws 
attention to the need for research on L2 students and their attributions of success and failure (Tse, 2000). Locke and Latham (1984) have drawn attention to the crucial relationship between goal setting and satisfaction with performance and the need for research in this area (Locke and Latham, 1984). Finally, Williams and Burden (1999) make a claim for the importance of research participants offering their personal judgments regarding definitions of learning success and failure (Williams and Burden, 1999).

The six aspects enumerated above will be scrutinized in the next six sections of this chapter. Subsequently, they will be brought together in the seventh section that presents a tentative theoretical definition of L2 language learners' sense of progress that also constitutes a summary of the main points presented in the next six sections. This definition is also the point of departure for the research questions that are proposed in the last section of this chapter.

\section{Sense of Progress as Metacognitive Knowledge}

Cognitive abilities that language learners bring to the undertaking of acquiring another language have received special attention in the field of applied linguistics since the 1970 s. These abilities are related to what learners understand about their own learning development (Wenden, 1986).

Regarding metacognition about the learning process, Wenden (1986) indicates that two dimensions are commonly recognized in the literature on cognitive development. The first dimension - knowledge about cognition - consists of "relatively stable information that human 
thinkers have about their own cognitive processes and those of others" (Wenden, 1986, p. 186). The second dimension - regulation of cognition - involves processes used to control and administer learning (i.e. planning, monitoring and checking learning outcomes). It could be tentatively postulated that sense of progress in L2 learning is more closely associated with the regulatory dimension of metacognition since it encompasses students' own assessment of their learning outcomes.

Wenden draws attention to the danger of looking at information on cognition - the first metacognitive dimension mentioned above - as a basis for drawing conclusions about the regulation of cognition. This danger stems from the failure of such procedure in informing researchers whether and how learners employ information on cognition during the actual process of learning. According to her, "to gain insight into this second dimension of metacognition would require a method of data collection that could tap as closely as possible learners' 'on-line' answers, i.e. their monitoring of the here and now in a direct immediate fashion" (Wenden, 1986, p. 198).

Rivers (2001) endorses a metacognitive dimensional classification distinct from Wenden's. He supports the claim that metacognition is discrete from cognition and consists of two categories of behavior: self-assessment and self-management. Self-assessment comprises the individual's capacity to evaluate his/her own cognition. Self-management, in turn, involves the individual's capacity to manage his/her further cognitive advancement. As maintained by him, self-assessment is a more crucial skill than self-management for two reasons. First, research has demonstrated that students with superior self-assessment abilities usually perform better in self-regulated language 
learning. Second, self- assessment is a behavior that emerges prior to self-management, that is, the latter cannot occur without the first.

In relation to the second aspect of the metacognitive dimensional classification scheme presented above, self-assessment could be identified as a crucial factor in promoting a sense of progress in L2. Once L2 students possess effective self-evaluation skills, they might become capable of assessing their own language learning progress more accurately and realistically. This assessment, in turn, might facilitate self-management and control of students' performance activities by themselves. Under this perspective sense of progress could be viewed as an overlapping and mediating metacognitive factor located between the metacognitive dimensions of self-assessment and self-management, as illustrated in Figure 1 below:

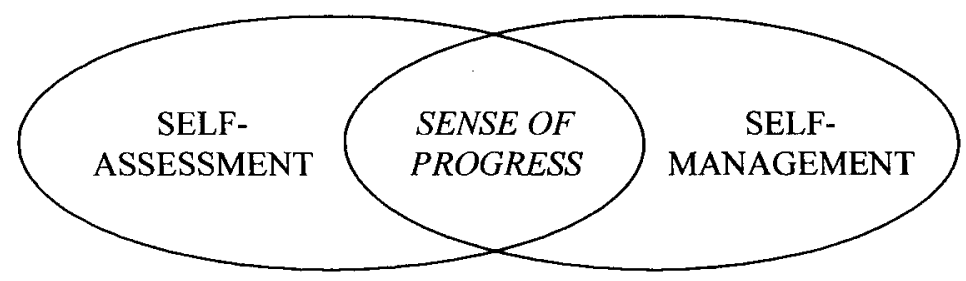

Figure 1. Self-assessment, Self-management and Sense of Progress

It could be suggested therefore that L2 learners' sense of progress is a component of metacognitive knowledge in the sense that it may be a resulting element of the metacognitive skill of observing and assessing the success of learning tasks (Cortazzi and Jin, 1996) as well as a prerequisite to the development of learners' metacognitive skill of regulating their own behaviors in the learning process. 


\section{Motivation and Sense of Progress}

The concept of L2 learning motivation has become a pivotal element of several theories of second language acquisition (Gardner and Tremblay, 1995). As indicated by Oxford and Shearin (1994), motivation is regarded by many to be one of the major determining factors in success in acquiring an L2 for the reason that "it determines the extent of active and personal involvement in L2 learning" (Oxford and Shearin, 1994, p. 12). It was brought up in the Introduction section of the present study that sense of progress in L2 learning might represent a component located within the wide-ranging construct motivation in language learning. The main goal of the present section is to contemplate the nature of the relationship between sense of progress and motivation in L2 learning taking as a springboard the assumption that the latter might be affected by the first.

Skehan (1989) calls attention to the fact that "the definition and study of L2 learning motivation have not been without their problems due to the great difficulty in demonstrating its effects" (Skehan 1989, p. 49). This difficulty undoubtedly also constitutes a theoretical issue when attempting to speculate about the relationship between motivation and sense of progress. In an attempt to tackle this shortcoming, the next three subsections of this chapter will examine three major models of motivation in L2 learning that have been proposed and recognized in the literature in the last decades. This examination is in keeping with the position that there is no particular motivational theory that allows for an understanding of all the aspects involved in motivational behavior (Landy and Becker, quoted in Gardner and Tremblay, 1995, p. 505). 


\section{Gardner's Model of Motivation}

The work done by Robert Gardner and Wallace Lambert involving motivation specific to language study is perhaps the most recognized in the field, having been the basis of a vast amount of research (Skehan, 1989). In the early 1970s, they established the well-known twofold classification for L2 learning motivational orientations - integrative vs. instrumental orientation. An integrative motivational orientation is possessed by people who identify positively with the target language, the people who speak it, the culture in which it is spoken, and want to be able to participate in this culture. Gardner and Lambert claimed that integrative orientation is a crucial motivational source for two reasons. First, it is strongly rooted on the personality of the learner. Second, it exercises its influence over an extended time interval to maintain learning efforts that are required to achieve language learning success (Gardner and Lambert, 1972). Instrumental motivational orientation, in turn, derives from the rewards that can be obtained if a language is known, such as professional and academic advancement. Gardner and Lambert hypothesized that an instrumental orientation is less helpful because it is not based on the personality of the learner and consequently is more dependent on external pressures - as a result the learner is less prone to employ effort to attain cumulative progress (Gardner and Lambert, 1972). It is important to point out that, in his most recent works on motivation, Gardner no longer presents integrative orientation as vital or meaningful (Oxford and Shearin, 1994).

In 1985, Gardner proposed a definition of motivation to learn an L2 as the amount of work and effort the individual invests to learn the language because of a wish to do so and the satisfaction 
experienced in this pursuit (Gardner, 1985). The components of this definition can be represented by the following equation:

\section{Motivation $=$ Effort + Desire to achieve a goal + Attitudes}

The first component - effort - refers to the amount of energy expended on the language learning enterprise and may include several aspects that do not relate specifically to learning a language such as compulsiveness, desire to please a teacher or parent, a high need to achieve, good study habits, etc. Gardner indicates the need to investigate the elements that direct this effort. The second component - desire to achieve a goal - involves the particular goal of learning a language. Finally, the third component - attitudes - represents "an evaluative response to some referent or attitude object, inferred on the basis of the individual's beliefs or opinions about the referent" (Gardner, 1985). Gardner adds that the accumulated research substantiation in the area of second language acquisition indicates that attitudes are associated with behavior, but not necessarily in a direct fashion.

In 1995, Gardner proposed an expansion of his motivational model that included new measures derived from the general psychological literature. These measures are related to individual characteristics that reflect motivation and were labeled by Gardner motivational antecedents. The motivational antecedents examined by him were expectancy and self-efficacy, valence, causal attributions and goal-setting (Gardner and Tremblay, 1995). Some of these antecedents will be discussed in the remainder of the literature review section. For the time being it will be proposed that the construct sense of progress could be regarded as an additional motivational antecedent within Gardner's expanded motivational model. Similar to the motivational antecedents mentioned 
above, sense of progress is an individual characteristic - individual learners develop unique perceptions about their learning progress - and it might have an effect on learners' motivation to learn the language - as was already suggested earlier.

\section{Williams and Burden's Model of Motivation}

Williams and Burden (1997) advocate a cognitive perspective on the study of motivation that revolves around individuals' decision-making about their own actions. This perspective implies that individuals are not at the mercy of outside forces over which they have no power. Within this cognitive standpoint, the aspect of choice is of fundamental importance since it is presupposes that "people have choice over the way they behave and, therefore, have control over their actions" (Williams and Burden, 1997, p. 119). Motivation is thus believed to be related to reasons why people choose to operate in particular ways and what elements have bearing on the choices they make.

Nonetheless, Williams and Burden recognize the constraints that arise from the exclusive adoption of the cognitive approach in the study of motivation. They claim that it might fail to include affective factors or social and contextual influences. For this reason, they deem it necessary to broaden this perspective by means of the adoption of a social constructivist view of motivation. This view focuses on the premise that each individual is differently motivated and makes his/her own sense of surrounding influences in ways that are particular to them. Additionally, it presupposes that an individual's motivation is dependent on social and contextual influences such as 
culture, context, social situation, significant other people and the individual's interaction with these people (Williams and Burden, 1997).

In this perspective, Williams and Burden present a definition of motivation that is fundamentally cognitive but fits within a social constructivist framework. They define motivation as "a state of cognitive and emotional arousal, which leads to a conscious decision to act, and which gives rise to a period of sustained intellectual and/or physical effort in order to attain a previously set goal or goals" (Williams and Burden, 1997, p. 120). This definition was the basis for Williams and Burden's model of motivation that separated three phases of the motivation process alongside a continuum: Reasons for doing something $\rightarrow$ Deciding to do something $\rightarrow$ Sustaining the effort, or persisting (Williams and Burden, 1997). As they claimed, the first two stages entailed initiating motivation whereas the third stage entailed sustaining motivation. Figure 2 illustrates the motivational phases and orientations in Williams and Burden's model.

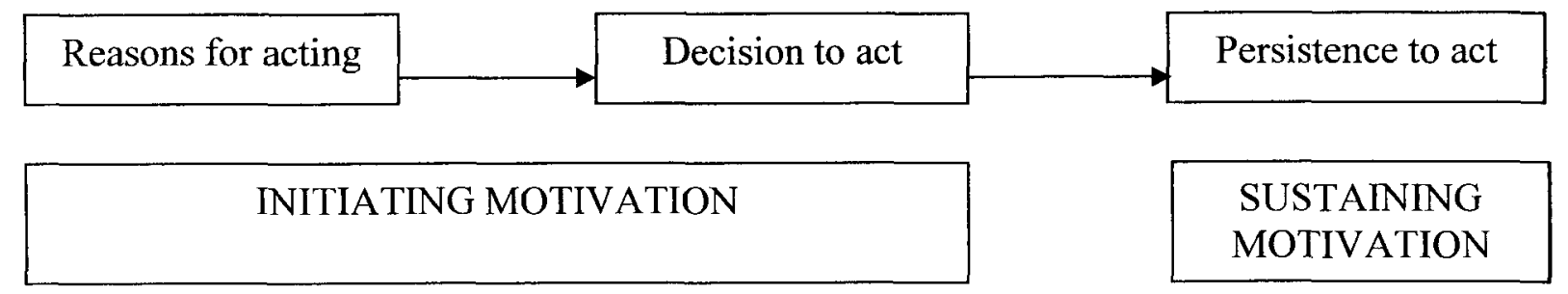

Figure 2. Williams and Burden's Motivational Model (Williams and Burden, 1997)

The decision to act component of Williams and Burden's model of motivation is argued to be influenced by a combination of both internal and external factors. Internal factors include intrinsic interest of activity, perceived value of activity, sense of agency, mastery, self-concept, attitudes, 
affective states, developmental age and stage and gender (Williams and Burden, 1997). According to them these internal factors intermingle with each other in a dynamic, non-linear fashion and the value that individuals ascribe to them will affect the level and extent of their motivation to carry out an activity. Besides affecting each other, internal factors are subject to the influences of external factors. Some critical external factors listed by Williams and Burden include significant others, the nature of interaction with significant others, the learning environment, and the broader context (Williams and Burden, 1997). In sum, their motivational model postulates that motivation entails decisions, and decisions will be rooted on individuals' construction of the world and internal attributes they bring to the situation. Furthermore, these decisions will be dependent on influences such as mediators and significant others.

In light of Williams and Burden's model of motivation, sense of progress could be seen as a "primordially" internal motivational factor that may be influenced by external factors. It is primordially internal because it involves learners setting their own learning goals, giving their own personal definitions and judgments of success and failure, being aware of their own personal strengths and weaknesses, and assessing their own learning outcomes. Additionally, it can be speculated that a positive and satisfactory sense of progress may cause the individual to continue not only to make decisions to act but also to sustain his/her effort in order to learn the L2. Therefore, sense of progress can be located both in the decision to act and persistence to act components in Williams and Burden's motivational model. Some external factors that may decisively shape learners' sense of progress are the nature and amount of teachers' feedback, 
classroom learning experiences, the nature and amount of praise received by significant others and societal expectations and attitudes.

\section{Dörnyei's Model of Motivation}

Dörnyei (2005) endorses a process-oriented approach to the study of L2 learning motivation that takes into account the dynamic nature and temporal variation of motivation. Such an approach would "account for the daily ups and downs of motivation to learn, that is, the ongoing changes for motivation over time" (Dörnyei, 2005, p. 83). He maintains that students' L2 learning motivation displays changeability in several varied learning time spans, ranging from a single L2 class to the situation of learning a language for months and years, or over a lifetime.

Consistent with this process-oriented perspective, Dörnyei (2005) presents a process model of L2 motivation that depicts some aspects of motivational development. This model categorizes the motivational process into several distinct chronological divisions that belong to three diverse motivational stages. Figure 3 illustrates the motivational stages and dimensions in Dörnyei's model.

\begin{tabular}{|c|c|c|}
\hline Preactional Stage & Actional Stage & Postactional Stage \\
\hline CHOICE MOTIVATION & $\begin{array}{l}\text { EXECUTIVE } \\
\text { MOTIVATION }\end{array}$ & $\begin{array}{l}\text { MOTIVATIONAL } \\
\text { RETROSPECTION }\end{array}$ \\
\hline
\end{tabular}

Figure 3. Dörnyei's Motivational Model (Dörnyei, 2005) 
The first stage - denominated preactional stage - involves the process of generation of motivation to learn the $\mathrm{L} 2$. This generated motivation is referred to as choice motivation because it "leads to the selection of the goal or task that the individual will pursue" (Dörnyei, 2005). The main motivational influences at the preactional stage include goal properties, values associated with the learning process itself, attitudes towards the L2 and its speakers, expectancy of success, learner beliefs and strategies and environmental support or hindrance (Dörnyei, 2005).

The second stage - labeled actional stage - is the stage where the generated motivation will be sustained and preserved while the specific action endures, developing into a new motivational dimension denominated executive motivation. According to Dörnyei, executive motivation is "particularly relevant to sustained activities such as studying an L2, and especially to learning in classroom settings, where students are exposed to a great number of distracting influences" (Dörnyei, 2005, p. 84). The main motivational influences at the actional stage include the quality of the learning experience, learners' sense of autonomy, teachers' and parents' influence, classroom reward and goal structure, influence of the learner group and knowledge and use of self-regulatory strategies (Dörnyei, 2005).

At last, the third stage - identified as the postactional stage - is the motivational phase that follows the conclusion of the action. In this stage, learners will make a retrospective assessment of the ways events occurred, which originates a motivational dimension termed motivational retrospection. The main motivational influences at this stage are attributional factors and selfconcept beliefs as well as received feedback, praise and grades. As stated by Dörnyei, "the way 
students process their past experiences in this retrospective phase will determine the kind of activities they will be motivated to pursue in the future" (Dörnyei, 2005, p. 84).

Two limitations of the process model of motivation described above are acknowledged by Dörnyei. First, it assumes that the actional process is "well-definable and has clear-cut boundaries" (Dörnyei, 2005, p. 86), which is not truthful since it is difficult to establish when an action starts and finishes in an educational context. The second problem is related to the fact that the actional process does not take place in isolation, without any interventions from other activities the learner is involved in. Individuals are often engaged in a number of parallel action procedures which means that a variety of action events can be concurrently in operation. For example, a new action may be commenced while the accomplishment of the preceding action is still being appraised. Dörnyei argues that "this is particularly valid for classroom contexts where student motivation and achievement are the product of a complex set of interacting goals and intentions of both academic and social nature" (Dörnyei, 2005, p. 86).

At this point in the discussion of Dörnyei's L2 model of motivation, it is necessary to locate in it a place for the construct sense of progress. It seems appropriate to view sense of progress as an additional motivational influence in all the three stages of the motivational model in question. In the preactional stage, learners' perceptions of their progress in previous learning experiences may influence goal setting and expectancy of success, which in turn may bear an impact on their choice motivation. In the actional stage, sense of progress could be an important factor in establishing the individual's control of his/her actions and promoting self-regulation in the learning process. In the preactional stage, In the postactional stage, sense of progress may be associated with causal 
attributions for learning successes and failures. Additionally, it may represent in this stage a crucial aspect in the beneficial construction of learning standards and strategies by learners - and its absence may lead to the harmful dismissal of the intention to learn and further planning (Dörnyei, 2005). The tentative placement of L2 learners' sense of progress in these three motivational stages implies that it might hold the same dynamic character and temporal variation as Dörnyei's concept of motivation.

As a final point in this section on motivation, it is important to highlight Dörnyei's observation that no theory has yet succeeded in representing motivation in its entire complexity (Dörnyei, 1998). For this reason, putting together aspects of different and contradictory approaches or selecting one single theoretical perspective constitutes a significant challenge when doing research on motivation (Williams, Burden and Lanvers, 2002).

\section{Sense of Progress and Individuals' Definitions of Success and Failure}

It was proposed in the introductory part of the present chapter that L2 learners' sense of progress is determined by individuals' definitions of successes and failures in L2 learning. This hypothesis also implies that these definitions are peculiar to each individual, i.e., what constitutes success for a particular learner in a given learning task may represent failure for another. These conceptual disparities across individuals about their language learning achievements will inevitably produce a multiplicity of perceptions about their L2 learning progress. 
As maintained by Frieze et al (1983), success and failure are not tangible experiences - they are psychological conditions that result of the perception of achieving or not achieving goals. The goal aspect in L2 learners' sense of progress will be dealt with in a subsequent section of this chapter. Frieze et al (1983) also argue that success is individually defined and influenced by societal norms and comparison with relevant others. In addition, they state that success has been defined in the research literature as "doing well at a challenging or effort-requiring task, exceeding one's expectations and defeating rivals, and doing well in specific situations" (Frieze et al, 1983, p. 13).

Williams and Burden (1999) point out four levels of variation which individuals' constructions of success and failure may display. First, they may vary from one subject area to another. Second, as mentioned above, they may differ from one individual to another. Third, in the school context, they may be influenced by "expectations and demands of the curriculum" (Williams and Burden, 1999, p. 199). Finally, they may also be shaped by interactions with significant other people. According to Williams and Burden (1999), all these levels need to be scrutinized when investigating individuals' conceptions of success and failure in learning settings.

Veroff (1977) identifies three standards for establishing definitions of success individuals may employ: task standards, personal standards and social standards. Task standards involve aspects such as types of tasks, task involvement and intrinsic qualities of the task. Personal standards consist of individuals' comparison of achievement goals based on their internal standards with objective levels of performance. Lastly, social standards refer to factors such as the individual's current performance and past achievements, social comparison and praise received by teachers and others (Veroff, 1977, quoted in Frieze et al, 1983, pp. 15-17). 
When investigating L2 learners' sense of progress, two specific factors need to be carefully taken into account. First, what L2 learners mean by learning successes and failures in view of their individual success values. Second, it is important to consider attributions regarding causes of performances perceived as successes or failures since an individual's convictions about the reasons for his/her performance are central determinants of how successful the performance is identified to be. This observation leads to the next section of this study that will delve into Attribution Theory and its paramount relevance to the development of the construct sense of progress in L2 learning.

\section{Attribution Theory and Sense of Progress}

Attribution Theory (henceforth AT) is a fundamental component in the theoretical and empirical consideration on the ways learners perceive their progress since this perception may be profoundly shaped by the attributions they make for their learning outcomes. Given the importance of AT for this study, this section aims to present a broad perspective on the construct in three subsections that address, respectively, a brief history of AT, issues concerning research on AT, and research on attributions in L2 learning.

\section{A Brief History of Attribution Theory}

AT, having emerged within the field of social psychology, claims that human beings are motivated to find out the causes of events in order to enhance their understanding of their environment. AT proposes that the subjective causes to which individuals attribute their past successes and failures to 
a large extent affect their motivational disposition underlying future action. If, for instance, an individual's past failure in a particular learning task is ascribed to low ability, the chances are greater that he/she will not continue to attempt the task. Conversely, if an individual accepts as true that his/her difficulty in a learning activity is attributable to insufficient effort or inappropriate learning strategies, he/she is more likely to try it another time (Dörnyei, 2005).

A vast amount of research on AT concerning the determinants of success and failure has been carried out in the fields of education, sociology and psychology. In the field of second language acquisition, however, research into attributions in L2 learning is still in an incipient stage in spite of the fact that its importance has been emphasized by authors such as Dörnyei (2005), Oxford and Shearin (1994), Crookes and Schmidt (1991) and Skehan (1989). As indicated by Dörnyei (2005), "the study of attributions in L2 learning is clearly an important line of investigation with much future scope" (Dörnyei, 2005, p. 80).

Fritz Heider (1958) was the first scholar to propose a psychological theory of attribution and is regarded by many as the responsible for the current growing interest in AT. He first wrote about AT in his book The Psychology of Interpersonal Relationships (1958) which played a central role in the origination and definition of AT. Heider's theory had as its underlying foundation the assumption that individuals need to find out the causes of events and to understand their environment. According to him, this causal search makes it possible a world that is more or less stable, predictable and controllable (Heider, 1958).

Heider also argued that this search for explanation of events occurs both in impersonal situations and in interpersonal relations and that our actions derive from personal or impersonal 
causality. Personal causality is dependent on the individual's control of his/her own actions. Impersonal causality, in turn, is subordinated to external forces (i.e. the environment). If one perceives an action as derived from personal forces, he is making a personal causality attribution. If, on the contrary, one attributes the event to causes external to him/her (which he/she does not have control over), he/she is making an impersonal causality attribution. Heider believed that the attribution of causality - either personal or impersonal - is a three-step process in which people have: (1) a perception of the action; (2) a judgment of intention; and (3) an attribution of disposition (Heider, 1958).

Although Heider was the first to develop a theory of attribution, it was Bernard Weiner $(1979,1983$ and 1986) who developed a theoretical framework for AT that has become a major research paradigm of social psychology. Weiner's AT also lies on the assumption that individuals look for causal understanding seeking answers to events (Weiner 1983). He defines causes as "constructions imposed by the perceiver (either an actor or an observer) to account for the relation between an action and an outcome" (Weiner, 1986, p. 22). According to him, these causes are particularly relevant when considering the reasons for success and failure in achievement-related situations.

The earliest version of Weiner's AT suggested that the four major attributions that individuals use to account for academic achievement (whether considered to be a success or a failure) are ability, effort, luck, and task difficulty. Graham (2004) points out that "effort, together with ability, is one of the attributions for success most commonly identified in western cultures and is generally held to have a positive influence on motivation" (Graham, 2004, p. 181). These four 
key attributions were categorized by Weiner in accordance with a bi-dimensional classification scheme of attributions. The first dimension (locus of causality) of this scheme is related to the internalization or externalization of attributions. In other words, this dimension is concerned both with "factors that arise from inside of us", internal attributions, and "factor that arise from outside of us", external attributions (Weiner, 1986). The second dimension that plays a role in the consideration of attributions is stability, which involves the question of whether or not a factor can be changed. According to Williams and Burden (1997), it should be evident that ability and effort are categories of internal attribution, while luck and task difficulty are external forms of attribution. It should also seem evident that ability and task difficulty are stable factors, whereas effort and luck are unstable, as shown in Table 1.

Table 1. Weiner's Original Model of Attribution

\begin{tabular}{|c|c|c|}
\hline \multirow{2}{*}{ Dimensions and Elements } & \multicolumn{2}{|c|}{ Locus of Causality } \\
\cline { 2 - 3 } & Internal & External \\
\hline Stable & ability & task difficulty \\
\hline Unstable & effort & luck \\
\hline
\end{tabular}

Nonetheless, later research has demonstrated that students point out other attributions for their perceived successes or failures such as: the teacher, being in a 'good' or 'bad' mood or feeling sick (Frieze et al, 1983). Moreover, Weiner himself acknowledged that "the potential causes of an achievement-related outcome are infinite" (Weiner, 1986, p. 137). Due to the fact that there are numerous possible attributions for success or failure, a third attributional dimension was included later by Weiner. It comprises attributions that individuals report are within or outside their control. 
This dimension is labeled controllability - and it refers to the level of volitional influence upon a cause (Weiner, 1986). According to Williams and Burden (1997), most people are prone to regard the amount of effort they put in a task as within their control and their ability to do well in a task as outside their control. Table 2 represents causes of success and failure, classified according to locus, stability, and controllability.

Table 2. Weiner's Expanded Model of Attribution

\begin{tabular}{|c|c|c|c|c|}
\hline \multirow{2}{*}{} & \multicolumn{2}{|c|}{ Locus of Causality } \\
\cline { 2 - 5 } & Stable & Unstable & Stable & Unstable \\
\cline { 2 - 5 } & typical effort & immediate effort & teacher bias & $\begin{array}{c}\text { Unusual help from } \\
\text { others }\end{array}$ \\
\hline Uncontrollable & ability & mood & task difficulty & luck \\
\hline
\end{tabular}

Williams and Burden indicate, however, that individuals diverge in the ways in which they perceive these attributions. For example, someone may regard luck as an internal and stable attribute when they say, "I guess I was just born lucky". Someone might also consider ability to be an unstable factor when declaring to do better on certain days according to how one feels (Williams and Burden, 1997).

Williams and Burden (1997) draw attention to the fact that the arrangement of attribution components and dimensions fluctuates significantly between individuals concerning particular events and activities. In short, "different combinations are likely to lead to different action outcomes" (Williams and Burden, 1997; p. 106). They also provide examples of these combinations and outcomes. For example, if a person believes that he/she does not have the ability to learn a 
foreign language and views this inability as a stable internal factor beyond his/her control, then that person will be unlikely to make an effort to do better. Conversely, if a person judges that language ability is an unstable skill that can be enhanced by hard work, then that person will be more likely to make an effort to improve.

In addition to formulating the tri-dimensional classification scheme of attributions presented above, Weiner highlights the role of emotions in attributional activity. He incorporates emotions as elements that arise when individuals make appraisals of and attributions for their performance. This led him to the formulation of a complex attributional model of motivation and emotion with seven main phases that describe the process through which emotions are developed in achievement-related contexts, as shown in Figure 4.

1. Individuals experience an achievement-related outcome that is unexpected, important and/or involves nonattainment of a desired goal

2. Individuals appraise their performance

3. The appraisal produces a positive or negative feeling of a certain intensity

4. The individual assigns a reason for the outcome

5. A number of attribution-specific emotions follow

6. The attributions are classified into causal dimensions

7. Further affective experiences follow

Figure 4. Weiner's Attributional Model of Motivation and Emotion (Weiner, 1986)

\section{Research on Attributions}

Weiner's basic attributional model postulated that "causal attributions are important mediators of subsequent performance" (Frieze et al, 1983, p. 6). These authors state that even though Weiner's original attributional model has been improved and expanded, most of the relevant research has corroborated the basic model This basic model disregards the possibility of varying definitions of 
success performance. It has as a starting point an "established" notion of success or failure, one established by the researcher, and explains the results on this basis. This practice does not allow for individual differences in success evaluations (Frieze et al, 1983).

It is necessary therefore to establish the differences between the objective success definitions used by researchers and the subjective appraisals of success offered by research participants. Weiner acknowledged that attributional decisions symbolize phenomenal causality - it is the causal world as viewed by the individual (Weiner 1986). He also recognized as a "methodological error" in AT research the "failure to conceptualize the situation as perceived by the experimental subject" (Weiner, 1983, p. 530). Frieze et al (1983) make a claim for a new and expanded model of the attribution process that should incorporate personal definitions of success and the emotions associated with evaluations of success (Frieze et al, 1983). However, a methodological limitation is that "subjects often do not have words readily available to describe their experiences" (Weiner, Russel and Lerman, 1979, p. 1213).

Bar-Tal and Darom (1979) add that "the predetermined use of the causes limits the understanding of the causal perception of success and failure in real situations and the antecedents which determine the use of the particular causes" (Bar-Tal and Darom, 1979, p. 266). These authors did a study with school children from elementary schools and they verified that "pupils tended to attribute success mainly to external causes and failure mainly to internal causes" (Bar-Tal and Darom, 1979, p. 266). Contrary to this perception, Williams, Burden and Al-Baharna (2001) argue that "prominent within the attribution literature is the notion of a "self-serving bias", which postulates that individuals are motivated by a need to enhance their self-esteem and tend to do so by 
ascribing success to internal factors and failure to external forces - the so-called "ego-protective behavior" (Williams, Burden and Al-Baharna, 2001, p. 182). In accordance with the latter standpoint, Oxford and Shearin (1994) add that "AT adds the concept that higher satisfaction occurs when success is self-attributed than when success is attributed to external factors" (Oxford and Shearin, 1994, p.21).

\section{Attribution Theory and L2 Learning}

According to Skehan (1989), what is relevant in AT to language learning are the causal factors to which success is attributed. If the stable factors of ability (such as intelligence and language aptitude) are deemed important, persistence to learn the L2 will be lower. If unstable factors (such as effort and luck) are prominent, motivation will be enhanced because the learner will "see himself as having a potential impact on learning progress" (Skehan, 1989, p. 52). Dörnyei (1990) identified an attribution about past failures component to L2 motivation and argued that these attributions are particularly important in foreign language learning contexts where L2 learning failure is a very frequent occurrence.

So far, the most significant research work concerning AT and L2 learning has been done by Marion Williams and Robert Burden. They advocate that the adoption of a constructive framework in the investigation of attributions. This framework is based on the assumption that different people define success in different ways and that progress in a learning enterprise is not an absolute, but instead it is conceptualized in "different ways by different cultures, groups and individuals" 
(Williams and Burden, 1997, p. 106). The ways individuals define success and perceive their learning progress can shape their attitude towards new learning tasks and new information.

Along the lines of this constructive perspective Williams and Burden (1999) conducted a small-scale research study by investigating young learners' attributions for success and failure in learning French at a school in the southwest of England. This study investigated the way in which students conceptualized the notion of "doing well" as well as their perceived reasons for their successes and failures. The results demonstrated that the majority of the interviewees conceptualize their achievement in terms of external factors such as teacher approval and grades. In addition, they found that the range of these conceptualizations increases with age. This increase corroborates Graham's (2004) acknowledgment that attributions are also subordinate to the context in which they are made (Graham, 2004).

In another study Williams and Burden found that the range of attributional categories developed by FL students was partially a function of their cultural background (Williams et al, 2001). In this study they examined a sample of Arab students among whom the notion of luck was never mentioned and ability was rarely cited. Nevertheless, these participants mentioned a wide variety of attributional factors related to the classroom environment, circumstances, exposure to the language, interest, strategy use, and support from others (Williams et al, 2001).

AT represents an important theoretical underpinning for the construct sense of progress in L2 learning given that students' perceptions about their learning progress may be influenced by causal attributions they make for their perceived language learning successes and failures. The fact that the arrangement of attribution elements and dimensions fluctuates significantly between 
individuals in relation to particular events and activities implies that different arrangements are likely to lead to different action outcomes such as deciding to employ more, less or no effort in the task of language learning. This means that performance attributions may also be a key determinant of L2 learners' actual performance and for this reason their investigation is of paramount importance.

\section{Locus of Control and Sense of Progress}

As indicated by Oxford and Shearin (1994), L2 learners must believe that they have some control over both their learning successes and learning failures. If they feel they are in control of the learning situation, it is likely that they will feel more responsible for their own learning and as a result become more autonomous and less dependent on teachers' guidance and supervision. This autonomy, in turn, may promote not only a sense of progress but also a sense of efficiency within learners so that they will wish to persist in learning the L2 (Oxford and Shearin, 1994).

Locus of control is a concept developed from the Social Learning Theory of Julian Rotter (1954). It draws a distinction between internals - individuals who feel personally responsible to what occurs to them - and externals - individuals who feel that their outcomes in life are determined by influences beyond their control. Most individuals are located at some point between these two extremes and many people are inclined toward one extreme or the other where significant life events are concerned. In addition, individuals typically differ in the ways they have a sense of control over negative as opposed to positive occurrences events (Findley and Cooper, 1983). 
Locus of control is considered to be a relatively enduring dispositional characteristic, although certainly modifiable through experience. It is also an antecedent to important social behaviors such as achievement-related activities, which has received extensive investigation (Findley and Cooper, 1983).

In a review of the literature undertaken with the goal of investigating the relationship between locus of control and academic achievement, Findley and Cooper conclude that internality and academic achievement are positively related. However, these authors also conclude that it cannot be inferred that locus of control causes academic achievement and that both locus of control and academic achievement are multidetermined. Mediators such as age, gender, locus of control scales and academic achievement measures appear to influence the strength but not the existence of the positive relation.

Weiner (1986) criticizes the notion of locus of control created by Rotter. According to him, Rotter's internal-external distinction had the shortcoming of confusing locus (external X internal) and controllability (controllable X uncontrollable). He argues that "locus and control, not locus of control, describe causal perceptions" (Weiner, 1986). Weiner regards it necessary to split Rotter's locus of control into two dimensions: locus and controllability. Weiner's controllability dimension was discussed previously in this study in the previous section.

With regard to L2 learning, AlFallay (2004) contends that a primordially internal locus of control seems to be beneficial in fostering sense of progress in L2 students. According to him, if students feel that they are in control of their own learning process, the learning environment will become more dynamic and stimulating (AlFallay, 2004). Williams and Burden (1997) state that 
research investigating locus of control and its relationship with learning revealed that individuals that hold a high internal locus of control display a strong predisposition "to seek information and use it appropriately in problem-solving tasks, to be active and assertive and to exhibit a high degree of exploratory behavior and excitement about learning" (Williams and Burden, 1997, p. 102).

\section{Learners' Goals and Sense of Progress}

Learning goals constitute a critical aspect in promoting sense of progress in L2 students given the fact that, without them, learners are not likely to have a clear assessment of their learning progress. Provided that students are successful in establishing and reaching learning goals, they are prone to achieve satisfaction with their learning progress and become further committed to these goals (Oxford and Shearin, 1994). Individuals who do not establish learning goals accomplish no change and are surpassed by those who set themselves the goal of improving their past achievements (Bandura, 1997).

According to Williams and Burden (1997), "learners should be helped to set their own goals and assess their own outcomes under conditions of minimal anxiety which promote realistic selfconfidence" (Williams and Burden, 1997, p. 139).

Veroff (1977) posits that the goal for any specific performance is based on ability estimates, assessment of the difficulty of the task, expectations based on past experiences and relationship of the present performance to longer range goals. This author also draws attention to the importance of the effect of goals on assessments of performance by arguing that "the 
discrepancy between desired and obtained performance is critical for subjective assessment of success" (Veroff, 1977, quoted in Frieze et al, 1983, p. 16).

Bandura (1997) adds that goals are unlikely to have much effect if there is little personal commitment to them since such commitment is affected by the degree to which goals are personally established. If goals are stipulated by others, individuals might not necessarily acknowledge them or feel obliged to achieve them. He also makes a case in favor of proximal learning goals by claiming that they bestow instant incentives and guides for current learning activities - in contrast to distant goals that are too remote in time to be helpful self-motivators. According to him, self-motivation is best maintained by bringing together a "long-range goal" (that sets the route of an individual's endeavor) with a series of achievable sub goals to guide and sustain this individual's efforts along the way. Subgoal attainments provide rising indicants of mastery that help to instill and verify a growing sense of personal efficacy. Making complex activities easier by breaking them down into a series of attainable subgoals also helps to reduce the risk of self-demoralization through high aspiration (Bandura, 1997).

Furthermore, Bandura argues that proximal goals are not merely minor passages to cherished greater goals. According to him, subgoals convey personal value to activities and aid in establishing the means for achievements. The fulfillment obtained from completing smaller deeds functions as its own reward all through the pursuit of higher goals (Bandura, 1997).

In addition to functioning as cognitive motivators, Bandura (1997) claims that proximal goals serve as a valuable instrument for promoting a sense of personal efficacy in individuals. Without criteria against which to evaluate their performance, people have not enough foundation for 
estimating how they are doing or for judging their capabilities. According to him, the need to concentrate on progress rather than on distal outcomes is crucial for people who need evidence that they are capable of high accomplishments. He adds that it is easier to inculcate beliefs of personal efficacy in an individual if the instruction and feedback focus not only on level of performance but also on mastery of strategies that allow this individual to attain progress (Bandura, 1997).

Oxford and Shearin (1994) highlight that L2 students' learning goals ought to be realistic but challenging and they should concern their ultimate L2 proficiency. From this ultimate proficiency goal, students should be able to develop immediate and attainable learning sub goals that are precisely what gives them a sense of progress. In this context, they claim that "teachers can help students build their own intrinsic reward system by emphasizing mastery of specific goals, not comparison with other students" (Oxford and Shearin, 1994, p. 24).

In sum, it seems evident that learning goals represent a crucial aspect in L2 learners' sense of progress for several reasons. First, they constitute personal benchmarks that aid learners in the assessment of their own learning outcomes. Second, it seems clear that the diversity of personal goals that learners establish for themselves will lead to personal differentiations of progress perceptions across learners. Third, learners should be successful in establishing and reaching learning goals in order to experience a sense of personal efficacy and proficiency as opposed to a sense of success or failure that stem from mere evaluations about performance accomplishment. 


\section{Summary - A Tentative Definition of Sense of Progress}

It has been argued in this chapter that the notion of L2 learners' sense of progress is directly linked to at least six crucial aspects. An overview of the theoretical developments related to each one of these aspects has been provided with the intention of building associations that could lead to a tentative definition of sense of progress in L2 learning. The definition that will be suggested is the following:

L2 learners' sense of progress is a component of metacognitive knowledge that involves learners' management and assessment of the outcomes (successes or failures) of their learning activities in face of their personally established learning goals. These successes or failures are individually defined and perceived differently by different learners. These definitions and perceptions may be influenced by internal or external factors and are strongly shaped by causal attributions learners make for their learning outcomes. Sense of progress is an important factor in promoting learners' control over their learning process and it may be a motivational influence in L2 learning.

As a final point, it is important to reiterate that no claims towards the unquestionable comprehensiveness and conclusiveness of the definition suggested above are being made. As previously indicated in this discussion, this provisional elaboration is a first step that serves as a theoretical springboard for the research conducted in the present study. 


\section{Research Question}

The perspective on theory adopted for this study regards it as a "valid blueprint for further action" (van Lier, 1988, p. 21). Under this orientation, theory plays a heuristic role as an instrument that aids in directing empirical investigation. Therefore, theory in this study is the guide for the conduct of research and also an aid in deciding what kinds of evidence are likely to be operative in answering the research questions.

The theoretical framework developed in this chapter is aimed at directing attention to pivotal aspects related to the notion of sense of progress. Given the perspective on theory presented above, the intention of this research study is to illustrate how the construct sense of progress and each of its aspects discussed above operate in terms of EFL and ESL learners' perceptions about them. The decision to investigate two learning settings as well as participants of different ages and educational backgrounds was motivated by the aspiration to promote a richer source of research data.

As recognized by a number of authors, L2 learners' perceptions and perspectives of their own language learning experiences are a crucial research need (Barkhuizen, 1998; Basturkmen and Lewis, 2002; Kumaravadivelu, 1991; Leki, 2001). In an attempt to address this need, the research question proposed for this study is the following:

How is each aspect discussed in this chapter linked to the notion of L2 learners' sense of progress in EFL and ESL settings? What are learners' perceptions and reported experiences about each aspect? How do these perceptions and experiences contribute towards the development of a sense of progress in these learners? 


\section{Chapter 3. Research Methodology}

This Chapter addresses research methodological aspects in three sections. In the first section, a discussion on methodological issues in research on L2 learners' sense of progress is undertaken. The second section presents the research methodology adopted for this study. It will be argued that qualitative methods may render particularly helpful data in research on sense of progress. Finally, the third section discusses methodological limitations encountered by the researcher while conducting this investigation.

\section{Methodological Issues in Research on Sense of Progress in L2 Learning}

As mentioned in the Introduction of the present work, sense of progress in L2 learning is a construct that has neither been addressed nor coined in theoretical and empirical work in the field of applied language studies. This novel character of the construct creates a considerable challenge not only to retrieve relevant literature but also to determine the research methodology for empirical investigation.

This challenge may be addressed by placing sense of progress within an established branch of the field of applied language studies. It may be looked at as an individual difference in language learning such as the extensively researched factors learning styles (Bailey et al, 2000; Ehrman and Leaver, 2003; Kolb, 1984, Reid, 1998; Riding, 1991), learning strategies (McIntyre, 1994; Norton and Toohey, 2001; O'Malley and Chamot, 1990; Oxford, 1990; Wenden, 1991), language aptitude 
(Carroll, 1973; Carroll, 1981; Carroll and Sapon, 1959; Grigorenko et al, 2000; Skehan, 1998, 2002; Sparks, 1995), and beliefs (Horwitz, 1985, 1987, 1988; Wenden, 1999, Woods, 1996).

A long-established methodology for the investigation of individual differences in L2 learning has been the identification of significant characteristics of individuals to help differentiate between them (Skehan, 1989). Such an approach has been inclined towards research of a positivistic type, normally involving large groups of participants who respond to questionnaires. The results of these questionnaires are usually subjected to statistical treatment such as correlational analysis (Brindley, 1984; Nunan, 1991) As an alternative, research on individual differences in language learning may employ experimental or quasi-experimental designs in an attempt to find out whether people with one or another collection of personal characteristics learn a language more or less effectively (Gersten and Baker, 2000; Schmidt, 2002).

Research of this nature has been criticized by authors who declare that it produces lists of variables that are presupposed to contribute in a considerable way to successful language learning and does not take into account the dynamic nature of individual differences (Clement and Gardner, 2001; Dörnyei and Skehan, 2003; McIntyre, 2002). For this type of research, numerous tests that are designed to measure these variables have been created and are used in a multitude of settings to determine learners' probability of success, such as governmental departments where employees need to undertake foreign language training. In those settings, it is not uncommon for $\mathrm{L} 2$ teachers to see students who score high in pre-training tests present serious learning difficulties and limitations over the course of the language instruction. 
Another criticism of positivistic-oriented research on individual differences is that it is aimed at specifying an L2 learner's fixed set of characteristics. According to Skehan (2002), this operates against the learner-centered notions of modern language education, especially because some of these characteristics were associated with outdated methodologies such as the audiolingual method (Skehan, 2002).

A number of studies in educational psychology and second language learning have attempted to measure the influence of some aspects such as attributions and locus of control on motivation, achievement and attained levels of proficiency in a second/foreign language (AlFallay, 2004). However, a large amount of this research has also been conducted under a positivistic paradigm that associates personal characteristics to numerical results. The significance of this research in terms of providing insights into the individual's thoughts and feelings has been questioned by authors such as Williams and Burden (1999). These authors claim that, in such research, the criteria for the investigation are pre-determined by the researcher and participants have no opportunities to offer their personal judgments on the issues being investigated. Such research trend reflects a perspective of psychology as akin to the natural sciences. Under this paradigm, researchers are unbiased spectators of the human condition which they attempt to calculate and control, and knowledge is impartial and outside the knower (Denzin and Lincoln, 2000).

An alternative research approach suggested by Williams and Burden (1999) is placed within a constructive framework. In this framework, learners' conceptions of themselves form the core of the learning process because they "profoundly influence the ways in which individuals make sense of new stimuli and construct new knowledge" (Williams and Burden, 1999, p. 193). In other words, 
the ways individuals view themselves as learners can shape their attitude towards new learning tasks and new information. Dörnyei (2005) corroborates Williams and Burden's standpoint and adds that there has been a recent trend to view individual differences in a situated mode, investigating their active interaction with the learning situation (Dörnyei, 2005).

This subjective and dynamic nature of individual differences in L2 learning requires an method in which psychological research is conducted within an interpretive and constructivist research paradigm (Denzin and Lincoln, 2000). Under an interpretive research paradigm, the role of the researcher is involved and subject and the role of the researched is one of active collaborator (Preissle and Lecompte, 1993). The researcher begins from the position of a searcher after personal meaning, as an investigator into the ways in which people make sense of situations in which they find themselves and why they proceed in the ways that they do (Salmon, 1988). The concern is, therefore what is taking place within individuals, and the main goals are meanings elicited from participants, intersubjective knowledge and clarification of discrepancies and bias (Salmon, 1988). Instead of aiming to identify and isolate within-person variables, this approach takes a more holistic view of the individual learner as a searcher after meaning and consequently views knowledge as subjective and associated with the knower (Salmon, 1988).

Within this interpretive paradigm, large scale correlational or experimental studies have been replaced by small-scale, personally orientated investigations of a qualitative nature (Tse, 2000; Williams and Burden, 1999; Williams, Burden and Al-Baharna, 2001; Williams, Burden and Lanvers, 2002; Williams, Burden, Poulet and Maun, 2004). As posited by Williams, Burden and AlBaharna, 2001, the increasingly popularity of qualitative research to investigation of individual 
differences in language learning is probably due to the increasing interest in an exploration of the ways in which individuals' thoughts and feelings about themselves as learners affect their approaches to and success in learning. The focus of this exploration is on "ways in which people construe the tasks with which they are faced in life and ways in which they draw upon their understandings in guiding their subsequent actions" (Williams, Burden and Al-Baharna, 2001, p. 172).

In the present study the research design will endeavor to keep in line with the qualitative/interpretive/constructive framework described above in an attempt to carry out a coconstruction of individuals' perceptions of their learning progress by both participants and the researcher. The aim of the investigation is, therefore, to illustrate how the concept sense of progress operates in terms of participants' perceptions of key aspects related to it.

\section{Methodology in the Present Study}

\section{$\underline{\text { Participants }}$}

The participants for this study were four Brazilian learners of English as a Foreign Language (EFL), two females and two males, attending an EFL course at university in a south-eastern city in Brazil; and two Brazilian learners of English as a Second Language (ESL), one female and one male, attending ESL courses at university in a mid-eastern city in Canada.

For the purpose of clarification, EFL will be defined as a "situation where English has no special status and where its communicative use is of low priority" (Navar, 1997, p. 29) and ESL 
will be defined as a circumstance where English is learned in the native milieu and the learning objectives are to interact successfully with native speakers (Navar, 1997). It is important to point out that, dissimilarly from the typical characteristics of ESL students established by the literature, the ESL participants in this study did not have as their main learning goal the integration into the native speaking community. In addition to academic and professional reasons, they came to Canada with the goal of reaching higher proficiency in English. They would return to their home country (Brazil) after one year and resume their regular activities in their workplaces. Hence, learning English for these learners did not constitute an emancipatory move towards the benefit of admittance and participation in the target culture (Peirce, 1995).

At the time of the data collection, the participants were at the intermediate level of English competence, as indicated by the descriptions of the courses they were attending. All of them had had several years of English instruction (minimum 5). At a macro level, the participants had comparatively uniform backgrounds since they shared the same mother tongue (Portuguese) and culture (Brazilian). At a micro level, however, they displayed heterogeneous features such as age (ranging from 15 to 55 years), level of education (ranging from second year of High School to Postdoctoral studies), language learning goals, and previous learning experiences. Table 3 shows participants age, level of education and learning setting (the goals and the learning experiences will be dealt with subsequently): 
Table 3. Participants' Age, Level of Education and Learning Setting

\begin{tabular}{|l|l|l|l|}
\hline Participants & Age & Level of Education & Learning Setting \\
\hline Sandra ${ }^{2}$ & 26 & Master's Degree & EFL \\
\hline Laura & 25 & Master's Degree & EFL \\
\hline Eduardo & 20 & Undergraduate & EFL \\
\hline Gabriel & 15 & High School & EFL \\
\hline Douglas & 48 & Post-Doctorate Studies & ESL \\
\hline Joana & 55 & Post-Doctorate Studies & ESL \\
\hline
\end{tabular}

Sandra and Laura were MSc students of Statistics who were taking an upper-intermediate EFL course (named Intermediate 4). They were in the same class as Eduardo and Gabriel. Eduardo was an undergraduate student of Engineering and Gabriel was a second-year High School student. Douglas was a physician and university professor and Joana was a university professor. They were in Canada for one year in order to complete their post-doctoral studies and they were both in the same intermediate ESL class. All the participants participated in this study for a period of three months.

An important aspect about the participants in this study is that shared the researcher's language and culture. This helped not only in the collection of the data (where the participants' native language was used) but also in the analysis of the data, where the researcher's in-depth knowledge of the participants' culture could assist in interpretations of their views in terms of their cultural backgrounds. For this reason, the researcher also played the role of a co-participant in this investigation, particularly in the ESL setting where she able to establish a closer and more equal

$2 \quad$ All participants' names mentioned in this study are fictitious. 
relationship with participants since they were acquaintances whom she frequently met in social events.

\section{$\underline{\text { Data Collection }}$}

The current research was carried out in accordance with the Tri-Council Policy Statement, 'Ethical Conduct for Research Involving Humans'. An application dossier, including all the ethical considerations of dealing with human subjects in the research, was submitted to the Ethics Committee of the university to obtain Ethics Clearance, and the proposal was approved before initiating data collection with the six participants.

The data were collected with the concern of attributing triangulation to the study. Triangulation will be defined as a "process of using multiple perceptions to clarify meaning, verifying the repeatability of an observation or interpretation" (Stake, 2000, p. 443). The main objective of triangulation is to put together information from different data sources, and/or data collected through different research methods. According to Watson-Gegeo (1988), it is an important strategy "for arriving at valid (or dependable) findings in ethnographic work" (Watson-Gegeo, 1988, p. 584).

Brown and Rogers (2002) list and define seven different types of triangulation: data, investigator, theory, methodological, interdisciplinary, time and location. Of these seven types the current study attempted to employ the following: methodological, interdisciplinary, time, and location. Methodological triangulation was attempted by the use of two data-collection procedures (interviews and written reflections). Interdisciplinary triangulation was endeavored by the 
consideration of perspectives of three disciplines (second language studies, education and psychology). Time triangulation was attempted by gathering data in multiple occasions over the course of three months. Finally, location triangulation was endeavored by the employment of two different learning settings to collect data (EFL and ESL).

The data collection modes were two oral interviews and six guided reflections ${ }^{3}$ written by participants. Interviews and reflections were carried out in Portuguese and all quotations from the interview transcript were translated into English by the researcher.

The first data collection mode in the study consisted of two sets of semi-structured interviews that were carried out in the beginning and in the end of the data collection stage. Initially, the researcher had an overall idea about the goal of each interview and had a schedule of questions to be asked, but allowed the questions to change as the interview unfolded. As stated by Kvale (1996), "a semi-structured interview has a sequence of themes to be covered, as well as suggested questions. Yet, at the same time there is an openness to changes of sequence and forms of questions in order to follow up the answers given and the stories told by the subjects. The research interview is an interpersonal situation, a conversation between two partners about a theme of mutual interest. It is a specific form of human interaction in which knowledge evolves through a dialogue" (Kvale, 1996, p. 124).

This type of interview method has been defended by many researchers working in a qualitative research tradition because of its flexibility in use and abundance in producing data (Block, 1995, 1998, 1999; Holstein and Gubrium, 1995; Woods, 1996). In addition, authors who favor the use of semi-structured interviews claim that they generate data that offer "an authentic

\footnotetext{
${ }^{3}$ See Appendices A and B for first interview schedule and stimulus material for guided written reflections.
} 
insight into people's points of view and experiences" (Silverman 1997, p. 100). Their main purpose is, therefore, to "obtain qualitative descriptions of the life world of the subject with respect to interpretation of their meaning" (Kvale, 1996, p. 124).

The first interview, which was conducted in the beginning of the data collection stage, was aimed at getting participants to start reflecting on the six aspects related to the notion of sense of progress presented in Chapter Two. In the second interview, which was conducted in the end of the data collection stage, the researcher clarified some points that were raised by participants in the written reflections by means of specific questions about these points.

In the first interview and in some reflections, the researcher endeavored to elicit narrative accounts from participants about their learning experience with English. For this reason, the first questions targeted the elicitation of stories about participants' previous language learning experiences in addition to stories about their present learning experiences that would provide access to their views on their learning progress. Agar (1980) and Woods (1996) defend the elicitation of data in form of narrative accounts. These authors contend that "personal narratives have been analyzed in other areas of study and rendered helpful in the analysis of the data" (Agar, 1980). Woods (1996) claims that participants' perceptions about their learning experiences "may not always be entirely consciously accessible, and subjects may, in responding to questions about generalized statements, answer according to what they would like to believe, or would like to show they believe in the interview context" (Woods, 1996, p. 27). In addition, he argues that learners' perceptions "articulated in the context of a 'story' about concrete events, behaviours and plans, are more likely to be grounded in actual behaviour" (Woods, 1996, p. 27). 
The second data collection mode in the study consisted of six semi-guided reflections written by participants on a biweekly basis over the course of a period of three months. Participants were asked to write responses to six open-ended questions that addressed their views on the theoretical aspects related to the notion of sense of progress presented in Chapter Two of this study. Additionally, they were asked to reflect on their English learning daily experiences over the time span of the data collection stage of the research. No limit was set for the responses and participants were told they could write freely.

Studies of L2 acquisition have long employed students' written reflections on their language learning, primordially by means of the use of diaries and journals (Allison, 1998; Bailey and Ochsner, 1983; Peck, 1996). As claimed by Tse (2000), "these self-reports provide a rich source of introspective information on how learners view their experiences in acquiring a L2" (Tse, 2000, p. 74). The reflections produced by the participants in this study were a combination of reflections, autobiographies and diaries, since they tackled not only participants' perceptions but also their English learning history and their concrete daily learning experiences. Such combination rendered useful in allowing the examination of participants' attitudes and experiences as well as the inclusion of a longer-range perspective for the study. As defended by Ellis (1989), written reflections can offer a helpful instrument for looking into a substantial number of student perceptions over time, validating, triangulating, and confronting conclusions derived from surveys and questionnaires (Ellis, 1989).

The written reflections were carried out on a biweekly basis in the belief that there would be a significant chance to capture the day-to-day fluctuations in participants' sense of progress. As 
mentioned above, the questions that guided the written reflections were targeted not only at theoretical aspects but also at participants' concrete learning experiences. The goal of the latter was to elicit anecdotes on learning experiences inside and outside the classroom they underwent in the two weeks prior to the submission of each reflection. This allowed participants to elaborate on what they liked and didn't like about their progress, what they did and what they didn't do, and how they felt about what was going on with their English.

On the whole, this study is based on the collection of narrative and opinion data from openended interviews and written reflections with a strong emphasis on elicitation and interpretation of anecdotal statements about concrete events and experiences lived by the participants.

\section{Data Analysis}

As noted above, the data collection modes in this study were two semi-structured interviews and six semi-guided written reflections. All these interviews and reflections with participants were conducted and analyzed in accordance with qualitative-oriented research procedures. (Glaser and Strauss, 1967; Strauss, 1987; Taylor and Bogdan, 1998). These procedures are discussed in the present section.

The data analysis approach adopted in this study is akin to the constant comparative method of qualitative analysis (Glaser and Strauss, 1967). This method combines explicit coding and theory development. In explicit coding, the data are converted into quantifiable form so that a hypothesis can be temporarily tested. Data is coded and then analyzed. An attempt is made to code all the relevant data that may corroborate a point, and then the data are systematically put together, 
evaluated and analyzed so that evidence for a given proposition can be constructed. In theory development, "theoretical notions are constantly redesigned and reintegrated as the researcher inspects and reviews his material, in order to generate theoretical ideas (new categories and their properties, hypotheses and intererrelated hypotheses)" (Glaser and Strauss, 1967). This author presents four stages of the constant comparative method: 1. comparing incidents applicable to each category; 2. integrating categories and their properties; 3. delimiting the theory; and 4. writing theory (Glaser and Strauss, 1967).

The main goal of the data analysis approach described above is the development of grounded theory (Strauss and Corbin, 1998), that is, theory that is originated from data and is systematically collected and examined through the research process (Strauss and Corbin, 1998). This method allows "data collection, analysis, and eventual theory to stand in close relationship to one another" (Strauss and Corbin, 1998, p. 12).

The remainder of the present section describes the data analysis procedures employed by the researcher in more detail. It is important to point out that the data analysis in this study did not occur in a linear fashion but rather followed a cyclical pattern, and this is reflected in the description that follows.

In the earlier stage of data analysis, an overall reading of the data was conducted and summary tables were produced for each interview and reflection, for each participant. This was done to facilitate information retrieval at a later stage of more profound analysis. The summary tables were also produced with the intent of "developing a story line for the coding, that is, deciding 
what concepts and themes will be communicated in the study and how the data should be organized" (Taylor and Bogdan, 1998, p. 150).

The next steps taken for the data analysis were axial coding and open coding of the data. Axial coding is "intense analysis done around one category at a time, in terms of the paradigm items (conditions, consequences, and so forth). This results in cumulative knowledge about relationships between that category and other categories and subcategories" (Strauss, 1987, p. 32). The categories for axial coding in this study were the six theoretical aspects related to the notion of sense of progress discussed in Chapter Two. For each category, analytical questions ${ }^{4}$ were generated as a means to direct the coding for each aspect. Subsequently the researcher scrutinized the data in detail by doing line-by-line analysis in order to search for answers for the questions. These answers were classified and categorized in subcategories that emerged during the axial coding process. In addition, the researcher produced a set of provisional theoretical memos that were tentative theoretical elaborations on the categories and subcategories.

Open coding was done simultaneously to axial coding. This procedure allowed the researcher to perceive new recurrent aspects emerging from the data that are also intrinsically associated with the notion of sense of progress. Due to the fact that these aspects (language skills and foreign language anxiety) surfaced after the literature review was concluded, they were not discussed in Chapter Two. This will be done in Chapter Four of the present study.

As defined by Strauss (1987), open coding is "the type of coding that produces provisional concepts that lead to issues pertaining to conditions, strategies, interactions, and consequences" (Strauss, 1987, p. 23). While doing the open coding, the researcher attempted to adopt the

\footnotetext{
${ }^{4}$ See Appendix C for samples of analytical questions that directed the coding.
} 
following procedures: 1. look for in-vivo codes (Glaser and Strauss, 1967), that is, terms used by the participants who were being studied; 2. ask specific questions about words, phrases, and sentences in a line-by-line analysis; 3 . move to dimensions that seemed relevant to given words, phrases, and sentences; and 4. find comparative cases for these dimensions (Glaser and Strauss, 1967). During this process further provisional theoretical memos were produced and they included new insights about the six theoretical aspects discussed in Chapter Two that had not been included previously.

Therefore, with the use of both axial and open coding, two kinds of analytical categories were generated: those which the researcher had established a priori to the commencement of the data collection, and those that have been abstracted from the specific research situation (Glaser and Strauss, 1967). Similarly to the procedure employed for the coding of the categories established prior to the commencement of the investigation, the novel emerging categories were also coded by means of analytical questions ${ }^{5}$.

The final step of the data analysis consisted in further reading through the coded data and the theoretical memos. During this process, the categories, subcategories and classifications were refined and more elaborate theoretical memos were produced. These memos were used at the writing stage of the study, during which the analysis received further revision, expansion and elaboration.

\footnotetext{
${ }^{5}$ See Appendix C for questions.
} 


\section{Methodological Limitations of Present Study}

Over the course of this investigation, the researcher encountered a few methodological challenges that did not constitute critical drawbacks since the study could be completed in spite of their presence. Nevertheless, these challenges are presented in this section as a way to account for eventual inaccuracies and inconsistencies of the study.

The first methodological limitation surfaced during the data collection and data analysis of this study. Since the researcher shared the participants' cultural background, she had to cope with the insider/outsider dilemma (Cumming, 1994). This dilemma places a challenge in achieving balance between insider and outsider perspectives. Being too familiar with the culture being researched may distort interpretation due to shared biases, whereas being too alienated from it inhibits an emic understanding of the culture. The emic view of research is related to "the researcher's attempt to infer the 'native' point of view and to describe the culture as its members understand it and participate in it" (Cumming, 1994, p. 688). The value of this orientation is the potential for new and unpredictable insights to emerge, as was the case in the present study. However, as defended by Pike (1967), it is important that the researcher has the opportunity to move between the emic and etic standpoints. The etic standpoint refers to the outsider's interpretation of events in a way that is not culture-specific. Pike (1967) adds that each analytic framework may inform the other through comparison and contrast, which is what the researcher attempted to do during this investigation. In addition, the researcher's response to this challenge tried to keep in line with Lazaraton's argument that "researchers researching their own culture must 
simultaneously maintain membership for the sake of their identity and detach themselves from the culture sufficiently to describe it" (Lazaraton, 2003, p. 689).

The second methodological limitation in this study is related to one of the data collection modes - interviews. As mentioned above, they do not necessarily allow access to the whole consciousness of participants for two reasons: participants usually do not have the words promptly available to describe their experiences (Woods, 1996) and the reliance on their retrospective subjective memory may render unsuccessful in providing accurate information about individuals' insights. Block (2000) argues that "interview data are not only reflections of research participants' memories of events (a cognitive phenomenon) but also reflections of how research participants relate to the interview context as actors in a particular context" (Block, 2000, p. 758). Under this perspective, interview data are not the production of an individual research participant but a "coconstruction of interviewer and interviewee through voices adopted by research participants in response to the researcher's prompts and questions" (Block, 2000, p. 758). The researcher attempted to keep this perspective in mind when conducting the interviews and analyzing the data derived from them.

The third methodological hindrance is associated with the use of theory as a starting point for the establishment of categories around which the data collection and analysis revolved in this study. According to Tesch (1990), "the categories may be derived from existing theories, but that procedure is tolerated more than it is encouraged" (Tesch, 1990, p. 85). This problem may be handled by means of consideration of the dual role of theory as described by van Lier (1988). This perspective regards theory both as a tool and as a goal. As a tool, theory is an aid in directing 
empirical investigation and it plays a heuristic role. As a goal, theory aids in the interpretation and ordering of empirical statements; it is "an economical and efficient way of abstracting, codifying, summarizing and storing information" (van Lier, 1988, p. 21). The researcher believes that both purposes are complementary and the role of theory can be considered from two angles: first, the initial role of theory in guiding the conduct of research; second, the part that research may play in the development of theories.

The last methodological challenge perceived by the researcher is the discrepancy in the number of EFL and ESL participants (four and two, respectively) in the study. This discrepancy occurred for two reasons: first, the difficulty to find Brazilian ESL participants willing to participate in the project; second, the withdrawal of one of the ESL participants from the research after the first month of the data collection stage. The researcher destroyed all the data that had been collected from this participant and she proceeded with the two remaining ESL participants and the four EFL participants. Due to the qualitative nature of this study, the researcher believes this issue did not constitute a serious setback for the investigation. 


\section{Chapter 4. Findings}

This chapter presents a qualitative analysis of participants' perceptions about their sense of progress in learning English as a Foreign and Second language. This analysis is based on participants' opinion statements and accounts of both their English learning histories and their daily English learning experiences over the course of three months. The focal point of this analysis is an interpretive one, based on the orientation presented in Chapter Three. Sense of progress is viewed as an individual difference (in which internal and external elements play a role) that may have an impact on L2 learners' motivation.

This chapter is divided in five sections. The first section provides a description of participants' sense of progress profiles that were produced after the data analysis was complete. These profiles depict each participant's overall orientation concerning their sense of progress. The second section addresses the research question that was introduced in Chapter Two. It presents the results of the data analysis that revolved around the six theoretical aspects related to the notion of sense of progress introduced in the same chapter: metacognition, motivation, individuals' definitions of success and failure, attributions, goals, and locus of control. In the third section, aspects related to sense of progress that were not introduced in Chapter Two (but that emerged during the data analysis process) will be discussed. These aspects are language skills and foreign language anxiety. Finally, the fourth section presents a reformulation of the definition of sense of progress presented in Chapter Two that includes new elements derived from the data analysis in this study. 


\section{Participants' Sense of Progress Profiles}

As defended above, sense of progress may be seen as an individual difference and is therefore unique to each individual L2 learner. For that reason, it is important to address this uniqueness in terms of each participant's peculiarities regarding their learning experiences and perceptions of their learning progress.

This section presents individual participants sense of progress profiles that were developed in the data analysis stage of this study. These profiles include the following aspects about each learner: their general self-assessment (how they generally evaluate themselves as learners), their

general perceived motivational orientation, their main learning goals, their primary definitions of learning success and failures, their causal attributions for their learning successes and failures, and other personal characteristics that seemed noteworthy to be included in their profiles.

\section{Participant 1: Sandra}

Sandra's main goals for studying English are to obtain an end-of-course certificate and take proficiency tests that will help her advance in her academic career. Sandra does not view her progress in learning English as a whole but she fragmented it according to language skills. She evaluates herself as a learner who has difficulties with oral expression and vocabulary, especially when it comes to reading non-technical texts. She reports having more facility with listening, writing and reading technical texts. Given all the time and effort investment she says she has put into learning English thus far in her life, she believes she should be at a higher level of proficiency. 
Her perceived motivation level is high and she says this is because she has been studying often and has been enjoying her activities in class. She is also satisfied to notice that her vocabulary is gradually expanding. In her view, doing well in English means making yourself understood and understand others both in oral and written language, that is, being able to communicate. In light if this criterion, she feels she is doing well because she can communicate in the classroom, although she has difficulties in oral expression. Her main attribution for her perceived success is effort.

\section{Participant 2: Laura}

Laura's main learning goals are to improve her reading and writing skills for academic purposes and to learn enough English in order to get a good job in the future. Similarly to Sandra, Laura is a learner who has more difficulty with oral expression, although reading, writing and listening do not seem to constitute problems for her. Her biggest challenge concerning oral expression is to overcome her shyness in class. She says she is making an effort to overcome her inhibition and for that reason she is beginning to feel a little more confident to speak. Her perceived motivation level for studying English is high and she says she feels more motivated when she believes her English is improving, that is, when she has a noticeable perception of learning evolution. Doing well for her in English consists in doing well in tests and classroom activities, and she believes she is doing well because she has been able to do her homework and classroom activities. Her main attributions for this perceived success are the opportunity to take an English course and effort. 


\section{Participant 3: Eduardo}

Eduardo's main learning goals are fluency development and to be able to travel abroad and perhaps pursue graduate studies overseas. He seems to be a very confident learner who has a very positive perception of his progress. He believes he is doing very well in English and his opinion about his own progress is based on his facility with the language and perceived improvement in all four skills, especially listening. He regards himself as a highly motivated English learner and the source of his perceived motivation for him was the realization that English is not only another school subject and it can be applied to several uses. Doing well for him means absorbing as much of classroom content as possible, being able to understand without too much difficulty, and expressing himself without having to think too much in his mother tongue. Given this perception, he believes he is doing well because he can express himself in class and understand people expressing themselves without too much difficulty. His attributions for his perceived success are effort and the teacher.

\section{Participant 4: Gabriel}

Gabriel is a younger learner whose main goal is to satisfy his parents by taking the English course. He views himself as an average learner who (similarly to Laura) has difficulties in oral expression due to shyness. Nevertheless, he reports having facility with the other skills, especially listening. His perceived level of motivation is medium because he feels he is getting a little "tired" of studying English for many years. He seems to be developing some resistance to English, which is causing him to feel lazy and not work so hard, although he continues to go to class and tries to get good grades. To him, doing well in English means to understand everything the teacher says, to 
understand a written text, to put your ideas in oral language and to do well in tests. Given this perspective, he deems his performance reasonable because although he feels he is doing well in listening and reading, he feels that his speaking skills need improvement. Another reason for his view of himself as an average learner is that he did not do very well in a few tests. He attributes his successes in listening and reading to access to English courses and media in English. He attributes his learning failures to laziness and lack of attention during tests.

Participant 5: Douglas

Douglas is an ESL learner who came to Canada for a one-year stay and with high hopes in terms of expectation of improvement in learning English without the help of formal courses. When he arrived in Canada his main goals were to express himself with richer vocabulary, without too many tense mistakes and with native-like constructions (the ability to form native-like constructions in English was also his main definition of doing well in English). Another goal he had was to improve his writing for academic purposes. A few weeks after his arrival in Canada, he found himself unable to communicate in English. For that reason, he decided to resort to English courses offered by the university where he was working. He also tried to take advantage of every opportunity to practice and learn. He is an industrious and self-confident learner who did not allow the difficulties to affect him too deeply and he seemed to be able to maintain a high level of motivation to learn in spite of the obstacles - he saw his learning failures as learning opportunities. Although he believed that his persistence was paying off, he felt he was not progressing as quickly as he had expected. He felt that he was still unable to form native-like constructions as he initially had hoped for. Reading did 
not seem to be a problem for him and he felt that his listening and writing were gradually improving. He attributes this slow learning progress to three factors: first, he spoke Portuguese all the time he was at home with his family; second, he did not have enough time to study English due to his involvement in several other courses and projects; third, he believed that he had reached an age when it is more difficult to learn a language. The progress he was actually able to achieve was attributed by him to his effort and immersion in an English-speaking environment, which he sees as the great secret for language proficiency development.

\section{Participant 6: Joana}

Joana is an ESL learner who (like Douglas) came to Canada for one year for academic purposes. Her main goals when she arrived in Canada were to master a basic English to find herself around in everyday survival situations (which was her definition of doing well) and improve her listening comprehension and pronunciation. After one year in Canada, she felt that the progress she had achieved was below her expectations, especially in listening comprehension. She felt slight improvement in pronunciation and speaking after taking private lessons and several courses at the university where she was working. Another factor that played a role in her improvement was the exposure to situations where she had no choice but communicate in English. She attributes her insufficient progress to emotional issues related to learning English, which the researcher perceived as a case of foreign language anxiety. She seems to be an extremely self-conscious learner who invests a lot of her ego in the learning process. Her motivation to learn English during her stay in Canada fluctuated according to her perceived evolution in learning - some days she would be more 
satisfied with her progress and therefore feel more motivated, and some other days the disappointment with her learning progress would make her feel less motivated.

\section{Participants' Perceptions about Theoretical Aspects of Sense of Progress}

In this section, the results of data analysis in regard to the theoretical aspects related to L2 learners' sense of progress discussed in Chapter Two (metacognition, motivation, individuals' definitions of learning success and failure, attribution theory, locus of control, and learners' goals) are presented with the aim of answering the research question of this study :

How is each aspect discussed in this chapter linked to the notion of L2 learners' sense of progress in EFL and ESL settings? What are learners' perceptions and reported experiences about each aspect? How do these perceptions and experiences contribute towards the development of a sense of progress in these learners?

This section is divided into five subsections that treat, respectively, the following aspects: self-assessment, motivation, definitions of learning successes and failures, attributions and locus of control, and learning goals. 


\section{$\underline{\text { Self-Assessment }}$}

As discussed in Chapter Two, self-assessment (individuals' capacity to evaluate their cognition) comes prior to self-management (individuals' capacity to manage their further advancement). This subsection presents ways the participants in this study reported they monitor and evaluate the success of their learning activities; in other words, how they reported they manage the metacognitive skill of self-assessment. The decision to focus on self-assessment results from the perception that sense of progress appears to be one of its resulting elements, as well as prerequisite to self-management. Self-management, however, is not treated by the present analysis because the focal point of this investigation is learners' perceptions of their learning outcomes rather than the use they make of cognition in more tangible learning processes.

Given the danger of scrutinizing learners' self-assessment by means of relying merely on participants' general and abstract statements, the interviews and written reflections contained two types of questions. The first type elicited participants' conceptions about self-assessment in terms of the criteria they use to assess themselves as English learners. The second type elicited concrete examples of specific learning situations that indicated progress or failure to participants.

In terms of participants' conceptions about self-assessment, the researcher looked at the criteria they reported to use when evaluating their learning outcomes. Figure 5 shows all the criteria mentioned by participants in response to the reflection question: What criteria do you use to evaluate your own progress in English?. The criteria are represented as they were worded by the participants. 
- ability to communicate

- comparison with classmates and other people who study English

- grades

- ability to speak, listen, write and read

- difficulty or facility in listening exercises

- teacher's comments

- understand what people say and be able to respond without too many agreement and tense mistakes

- performance in everyday situations outside the classroom

Fig. 5 - Criteria participants reported to use to evaluate their own learning progress in English

One participant not only listed the criteria she employed for assessing her learning progress but also established a "ranking order" for them. Laura (an EFL participant) reported that her criteria were, in order of importance, grades; ability to speak, write and read; difficulty or facility in listening exercises; and comparison with classmates or other people. Based on these criteria, she views herself as an average learner. According to her, this is due to the fact that although she has no difficulty in reading, writing and listening, she displays some difficulty in speaking.

After they listed the criteria shown above, participants were asked to generally evaluate themselves as English learners based on these criteria. Their answers are summarized in Table 4:

Table 4 - Participants' general self-assessment based on their own criteria

\begin{tabular}{|l|l|}
\hline Sandra & There are aspects that need to be improved. \\
\hline Laura & $\begin{array}{l}\text { Average - reading, writing and listening are not difficult but speaking is } \\
\text { still a little difficult. }\end{array}$ \\
\hline Eduardo & $\begin{array}{l}\text { Good, because does not have problems with grades and listening } \\
\text { difficulties, and is interested and dedicated. }\end{array}$ \\
\hline Gabriel & Reasonable. \\
\hline Douglas & $\begin{array}{l}\text { Bad because he is going back home (Brazil) without fluency in spoken } \\
\text { English. }\end{array}$ \\
\hline Joana & $\begin{array}{l}\text { Sometimes she thinks her effort was worth it, other times she thinks it } \\
\text { was all a big failure and she should give up. What afflicts her the most is } \\
\text { her inability to listen. }\end{array}$ \\
\hline
\end{tabular}


With regard to concrete situations that indicated learning success or failure to participants, the researcher worked through all the data to pinpoint specific situations in which participants evaluated themselves. These situations did not stem from a single question, but from several different questions in the interviews and reflections. Due to the nature of the reflection questions (some of them were rephrased and repeated over the course of the investigation) the participants had various opportunities to provide of these concrete situations. Three of the reflection questions attempted to elicit these situations. Additionally, participants provided examples of concrete situations as responses to questions that did not address them directly.

Table 5 displays concrete situations where participants reported they assessed themselves as English learners. These situations were appointed by participants as indicators of their learning progress or failure in specific situations. They were coded and subsequently classified in accordance with two sets of categories developed by the researcher. The first set of categories differentiates the situations between classroom-related and outside the classroom. The second group of categories classify the situations according to language skills (speaking, listening, reading and writing), social interactions in English and miscellaneous situations that are not related to the two categories previously mentioned. 
Table 5 - Concrete situations where participants reported they assessed themselves as English learners

\begin{tabular}{|c|c|c|}
\hline & Classroom-related situations & Outside the classroom situations \\
\hline Speaking & $\begin{array}{l}\text { Self-expression } \\
\text { Answering teacher's questions }\end{array}$ & $\begin{array}{l}\text { Self-expression in a content course delivered in English } \\
\text { Possibility of questions about paper presented at a } \\
\text { conference (scared about it) }\end{array}$ \\
\hline Listening & $\begin{array}{l}\text { Listening exercises } \\
\text { Listening to teacher talk and peer talk }\end{array}$ & $\begin{array}{l}\text { Watching TV shows } \\
\text { Watching movies } \\
\text { Listening to songs }\end{array}$ \\
\hline Reading & $\begin{array}{l}\text { Scientific articles } \\
\text { Technical texts } \\
\text { Use of dictionaries }\end{array}$ & \\
\hline Writing & $\begin{array}{l}\text { Writing assignments } \\
\text { Request of an article (e-mail sent to } \\
\text { author) } \\
\text { Formal request }\end{array}$ & \\
\hline Social & & $\begin{array}{l}\text { Dinner with English teacher } \\
\text { Movie session at teacher's place followed by discussion } \\
\text { Had two High School teachers for supper } \\
\text { Group speaker in a discussion group seminar } \\
\text { Use of "survival English" on the streets } \\
\text { Phone conversation with American } \\
\text { Self-expression in a bank } \\
\text { Conversations with foreign English speakers (German and } \\
\text { American) } \\
\text { Answering questions at supermarket check-out } \\
\text { Understanding answers to own questions }\end{array}$ \\
\hline Other & $\begin{array}{l}\text { Recall of grammatical facts } \\
\text { In-class activities } \\
\text { Homework activities } \\
\text { Assessment from teachers and peers } \\
\text { Tests } \\
\text { Mental translation from Portuguese to } \\
\text { English }\end{array}$ & \\
\hline
\end{tabular}

The classification of the situations in terms of language skills will be dealt with more extensively in a later section in this study. ESL participants were able to enumerate more outside the classroom situations than EFL participants. This is due to the fact that EFL students are for the most part restricted to the classroom situation in terms of language learning, practice and assessment.

With regard to self-assessment, an aspect that arose from one of the participants' comments (Douglas) was the contrast between self-assessment and external assessment. He arrived in Canada 
with high expectations in terms of language development but in his view these expectations were not met. He had the impression was that his learning speed was slower than what he would like. Nevertheless, he reported that people around him would praise his progress in English. This may indicate that the external assessment he obtained was more positive than his self-assessment as an English learner:

D: I had higher expectations. Normally in the technical professional-related issues I don't have a lot of difficulty. (...) But maybe I had expectations given my initial expectations, maybe my expectations were higher initially. Then you end up thinking that your speed is slower than everybody else's. I think everyone has their own pace. When you talk to a native speaker, he says, "it is estimated that the time for a foreigner to speak English like a Canadian is 8 years". Well, in 6 months, when people say, "you improved", let's say, the external evaluation is better than the internal evaluation. You have a wish that is different from your possibility.

As a final observation for this section, it is important to point out that the findings presented above do not aim to provide a comprehensive account of L2 learners' self-assessment and metacognition. As argued by Williams and Burden (1997) point out, metacognition must incorporate information on aspects related to the self, and the way in which these influence cognitive operations (Williams and Burden, 1997). These factors involve the knowledge about everything that individuals believe about themselves and others as learners. The nature of this knowledge is far beyond the scope and the goal of this section, which was to present general criteria and concrete situations against which participants report they judge their learning progress. 


\section{$\underline{\text { Motivation }}$}

As argued above, motivation seems to be intrinsically related to L2 learners' sense of progress. However, the exact nature of this relationship is still unknown since very little research about it has been carried out. This subsection presents participants' perceptions on their motivation to learn English and ways they related these perceptions to their perceived learning progress. As mentioned in Chapter Two, demonstrating the causes and effects of L2 learners' motivation is a challenging undertaking. For this reason, the upcoming analysis does not claim to establish an all-encompassing account of the relationship between motivation and sense of progress.

This subsection will focus on participants' initial and ulterior perceptions on their learning motivation and learning progress over the course of this investigation. The initial perceptions include analysis of data elicited in the first interview. The later perceptions involve analysis of data elicited in the written reflections.

Initial Perceptions on Motivation and Sense of Progress

As suggested in Chapter Two, within Gardner's (1995) expanded motivational model sense of progress could be viewed as an additional motivational antecedent among expectancy, self-efficacy, valence, causal attributions and goal-setting (Gardner and Tremblay, 1995). Given this perspective, the researcher decided to investigate whether the participants perceived sense of progress as a motivational antecedent; in other words, whether individuals viewed a positive and satisfactory sense of progress as a factor that motivates them to learn English. 
Keeping in mind the difficulty to establish a positive direct relation between perceived satisfaction with progress and perceived motivational level, the researcher devised the following table (Table 6) in an attempt to delineate primary connections between the two constructs. The answers included in the table were elicited by interview questions about satisfaction with progress and participants' perceived motivational level.

Table 6 - Participants' initial perceptions on their satisfaction with learning progress and perceived motivational level

\begin{tabular}{|l|l|l|}
\hline PARTICIPANTS & \multicolumn{1}{|c|}{$\begin{array}{c}\text { SATISFACTION WITH } \\
\text { PROGRESS }\end{array}$} & \multicolumn{1}{|c|}{$\begin{array}{c}\text { PERCEIVED } \\
\text { MOTIVATIONAL } \\
\text { LEVEL }\end{array}$} \\
\hline Sandra & $\begin{array}{l}\text { Could be better (at a higher } \\
\text { level) }\end{array}$ & Very high \\
\hline Laura & $\begin{array}{l}\text { Feels she lost a little of her } \\
\text { English (after a gap in studies) } \\
\text { and is trying to catch up }\end{array}$ & Very high \\
\hline Eduardo & Satisfied & Very high \\
\hline Gabriel & Satisfied & High \\
\hline Douglas & Slow progress & Very high \\
\hline Joana & $\begin{array}{l}\text { Not very satisfied (below } \\
\text { expectations) }\end{array}$ & Medium \\
\hline
\end{tabular}

Some observations about the table above lead to a few tentative insights. First, the two participants who said they were satisfied (Eduardo and Gabriel) reported high levels of perceived learning motivation. Eduardo associated his motivation with the effort he puts in learning English in spite of his time constraints:

E: I would say my motivation level is very high, because as I am studying and doing my BSc, I don't have a lot of time. So, in order to be able to study English, write the placement test and try to 
maintain good grades to get a scholarship, I had to dedicate a lot, so in my opinion my motivation level is very high.

Gabriel was the only participants who promptly associated motivation and sense of progress:

G: I think my motivation level is very high, because of the feedback 1 had. When you feel improvement in your learning you think that this subject is going to be better, that is, better than the others you cannot assimilate. Therefore, you end up enjoying the subject, and motivation increases.

Three other participants (Sandra, Laura and Douglas) declared they are not very satisfied with their learning progress. Nevertheless, they also reported high levels of motivation. The exception to this pattern is Joana who declared that at the moment of the interview her motivation level was higher than in the months before. She associates this perception with the methodology and the teacher she had a few weeks before the interview:

$\mathrm{J}$ : What happened is that this course given by this new teacher is making me want to learn. Because, if I was going to have the same teacher again, I wouldn't study, I would quit. (...) The methodology was not a good methodology. (...) The course did not satisfy the very good ones, because they thought they were not improving, and I think it didn't satisfy the very weak ones. (...). And the previous teacher did not have this concern about the development of each individual student like the new one. 
The researcher decided to investigate why the three students who said they are not so satisfied reported they are highly motivated. In Sandra and Laura's case, their motivation was associated with enjoyment of learning the language. When asked how they would classify their motivational level, they both replied that it is very high because they "enjoyed learning English". In Douglas' case, it was precisely the dissatisfaction and the challenge that was motivating him to invest more effort in learning English:

D: I came to Canada with the following reasoning: now I am going to learn English no matter what. I am no longer going to attend any English classes, I am no longer going to do anything, I got tired of it all. I had promised that to myself. But the interesting thing is that, when you face the difficulty you motivate yourself to make use of all the instruments that people offer you.

The analysis above demonstrates the enormous difficulty of relating motivation and sense of progress in a direct fashion. Sense of progress may be a motivational antecedent but it is certainly not the major one given the fact that motivation can originate even when there is a sense of lack of progress. Furthermore, the association between sense of progress and motivation was not instantly established by the participants. This is probably due to participants' diverse views on what constitutes motivation (effort, enjoyment, desire to overcome a difficult challenge, etc) as well as their diverse views on factors that promote motivation (improvement in learning, classroom methodology, teacher, etc). This conclusion reiterates Williams and Burden's (1997) claim that the basic premise for achievement motivation is that "people differ quite markedly in their need to achieve or to be successful" (Williams and Burden, 1997, p. 112). Additionally, it reinforces the 
need for a social constructivistic view of motivation that regards individuals as differently motivated, what causes them to "make their own sense of surrounding influences in ways that are particular to them" (Williams and Burden, 1997, p. 120).

\section{Later Perceptions on Motivation and Sense of Progress}

Four weeks after the first interview, the researcher submitted reflection questions about participants' perceived motivational levels. The repetition of themes across interview and reflection questions was aimed at three goals: to obtain triangulation for the study, to attempt to delve more deeply into participants' perceptions, and to attempt to track participants' perceived fluctuations (if any) in their motivational levels.

Overall, participants' reported motivational level was the same after four weeks. The exceptions were Gabriel, who reported that his motivation level was "medium" (as opposed to high in the interview); and Joana, who reported she felt a slight increase in her motivation level because she noticed evolution in her learning.

In light of Dörnyei's (2005) process-oriented dynamic chronological approach to motivation (presented in Chapter Two) a reflection question attempted to address this approach by asking participants about moments and situations when they felt that their motivation levels would increase and decrease. In addition, they were asked about the factors that, in their view, caused their perceived motivation levels to increase and decrease. A list was produced with all these moments, situations and factors. After all these elements were grouped together, it was detected that most of them could in a way or another be related to the notion of sense of progress. Figure 6 below 
displays the list that was produced and it includes items as they were worded by participants. Items marked with a * can be, in the researchers' view, related to sense of progress.

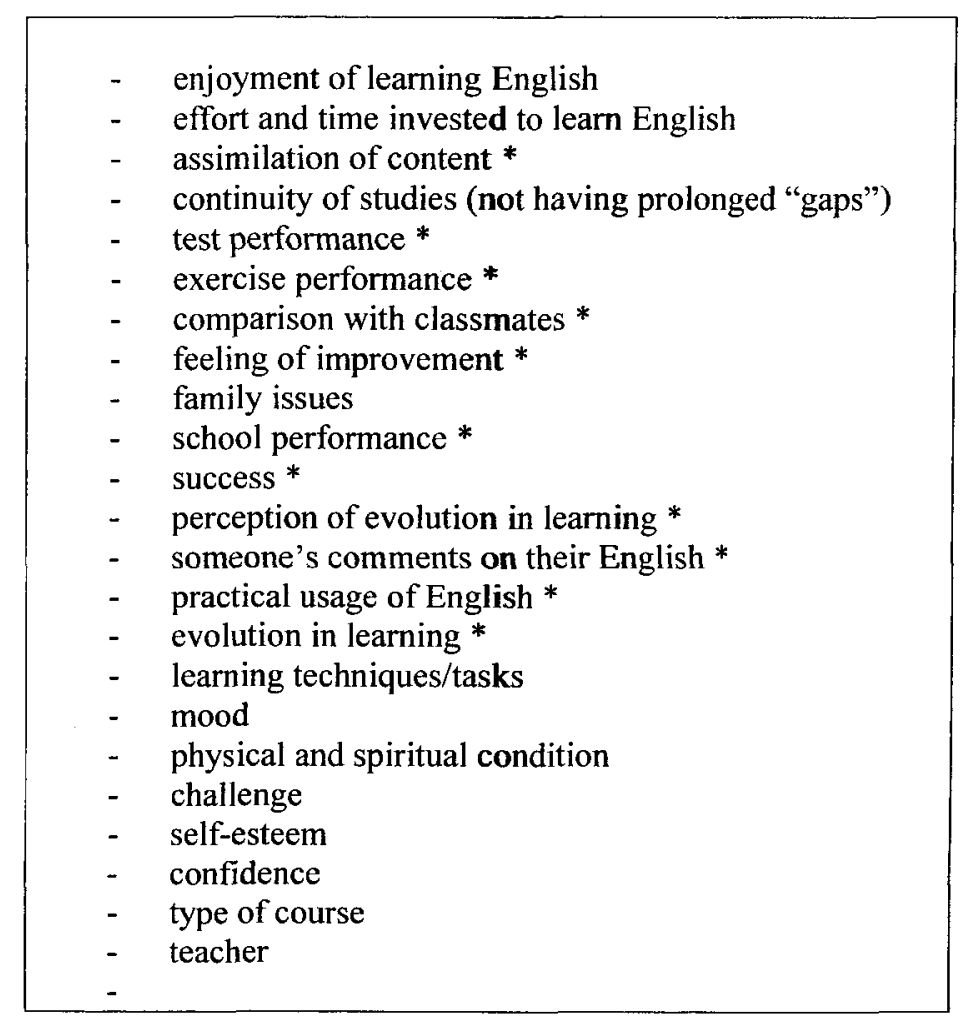

Figure 6 - Elements that participants reported to affect their motivation to learn English

We can see that a significant number of the items listed above are related to participants' perceptions about their progress in learning English. This might reiterate the importance of fostering in learners a sense of progress in order to keep them motivated to learn, as in Laura's case:

L: My motivation increases or decreases when I believe I am improving or not in English. When I don't do well in a test or when I cannot do the exercises I feel less motivated to keep on studying. 
And if I notice that other people in the classroom did well in the exams I feel even less motivated. On the other hand, if I manage to do well I feel more like learning and keep on studying.

Another noteworthy aspect concerning motivation detected during the data analysis is the fluctuation some participants reported in their motivation levels. This fluctuation was reported by some participants as taking place over the course of a lifetime of English instruction or over the course of the three months of the present study. Eduardo, for instance, is a learner who has perceived increasing motivation levels since he started studying English:

E: My motivation certainly suffered variation since I began studying English. As time went by my motivation increased because I began to notice that English has several uses and was not just another school subject, because I could read and understand several texts (scientific or informal).

As a final observation for this section, it is patent that teachers need to foster a sense of progress in their learners given the fact that it seems to play an important role in students' motivation. However, the researcher acknowledges that several more in-depth studies are needed to investigate the nature of the relation between sense of progress and motivation. 


\section{Definitions of Success and Failure}

The following analysis is underlined by the assumption that learning successes and failures are not tangible experiences, but rather they are psychological conditions and therefore will have great variation across individuals. This subsection is aimed at the question of what learners mean by learning successes and failures in view of their individual values.

This issue was addressed by a reflection where participants were asked about what, in their opinion, means to do well and poorly in English. In addition, participants were asked to provide examples of situations they experienced (inside or outside the classroom) where they think they did well or and poorly.

For the purpose of organization, this subsection will be divided in two further subsections that address, respectively, what participants mean by learning successes and what they mean by learning failures.

\section{Definitions of Learning Success}

A preponderant and recurrent view participants held about learning success was the ability to use English as a tool for oral and written communication. This trend was detected both in the EFL and the ESL situations. In the EFL setting this communication is restricted to the classroom environment whereas in the ESL setting the participants' focus was on communication in situations outside the classroom. Second to communication, listening comprehension emerged as a crucial factor in fostering a sense of progress in participants, either inside or outside the classroom situation. 
Table 7 below presents participants' conceptions of doing well in English as well as examples of situations where they believe they experienced learning success. In order to classify these conceptions and situations, the researcher employed the three standards proposed by Veroff (1977), presented in Chapter Two of this study. These standards are, respectively, task (related to types of tasks, task involvement and intrinsic qualities of tasks), personal (related to an individuals' comparison of achievement goals with objective levels of performance), and social (related to factors such as social comparison and praise received by others). Each conception and situation depicted in Table 7 received a label according to Veroff's standards ( $\mathrm{T}$ for task, $\mathrm{P}$ for personal, and S for social). 
Table 7 - What participants mean by learning success

\begin{tabular}{|c|c|c|}
\hline PARTICIPANTS & DEFINITIONS OF LEARNING SUCCESS & $\begin{array}{l}\text { EXAMPLES OF LEARNING } \\
\text { SUCCESSES }\end{array}$ \\
\hline$\overline{\text { Sandra }}$ & Ability to communicate (T) & $\begin{array}{l}\text { Was able to request an article via internet } \\
\text { (T) } \\
\text { Able to understand movies and TV } \\
\text { shows (T) } \\
\text { Able to read articles and technical texts } \\
\text { in English (T) }\end{array}$ \\
\hline Laura & Do well in tests and classroom activities (P) & Had a successful phone conversation $(\mathrm{T})$ \\
\hline Eduardo & $\begin{array}{l}\text { Ability to absorb as much of the content as } \\
\text { possible (P) } \\
\text { Ability to understand "what happens in } \\
\text { English" (such as the gist of a conversation) } \\
\text { (T) }\end{array}$ & $\begin{array}{l}\text { Able to express himself and understand } \\
\text { in the classroom without much difficulty } \\
\text { (T) }\end{array}$ \\
\hline Gabriel & $\begin{array}{l}\text { Ability to understand what teacher says (T) } \\
\text { Ability to understand a text }(\mathrm{T}) \\
\text { Ability to convert your ideas into oral language } \\
\text { (T) }\end{array}$ & $\begin{array}{l}\text { Was able to understand every word of a } \\
\text { listening exercise (T) }\end{array}$ \\
\hline Douglas & $\begin{array}{l}\text { Ability to communicate with native speakers } \\
\text { with few mistakes (T) } \\
\text { English not being a barrier to professional } \\
\text { development (P) } \\
\text { Ability to watch TV in English with little } \\
\text { difficulty (T) } \\
\text { Ability to write a technical text or project (T) } \\
\text { Ability to exchange short messages on the } \\
\text { internet }(\mathrm{T})\end{array}$ & $\begin{array}{l}\text { Was able to express himself in a specific } \\
\text { content course delivered in English }(T)\end{array}$ \\
\hline Joana & $\begin{array}{l}\text { Ability to communicate with a minimum of } \\
\text { confidence in practical survival situations (T) }\end{array}$ & $\begin{array}{l}\text { Was able to express herself at the bank } \\
\text { (T) } \\
\text { Was able to answer simple questions on } \\
\text { the street or elevator (T) } \\
\text { Scored } 100 \% \text { in a listening exercise in } \\
\text { class (P) } \\
\text { Participated in a class debate and } \\
\text { received positive feedback from } \\
\text { classmates and teacher (S) }\end{array}$ \\
\hline
\end{tabular}

According to the classification above, it seems that the task standard was preponderant when participants tried to define what constitutes learning successes. This might be an indication of the importance of tasks in the L2 classroom as a crucial mechanism to nurture a positive sense of 
progress in learners, as long as they enable learners to experience a feeling of success and satisfaction.

The two ESL participants provided answers that indicated that the ability to communicate with native speakers in everyday situations was their main definition of learning success. When Douglas arrived in Canada, that communication was extremely difficult for him. Nevertheless, he was able to determine what his learning needs were and took action to meet those needs. He seems to be a learner with a high level of learner autonomy since he actively interfered to take the control of his learning process (Rivers, 2001). As the following quote demonstrates, this appears to have had a positive impact in his learning:

D: I got a haircut yesterday, and I had got a haircut 3 or 4 months ago. It was visible: I was already able to communicate, because the first time I went to the hairdresser I felt like crying, I had to make this gesture with my finger (does a scissor with fingers), I didn't even know how to say "comb your hair". Based on this experience, which was tough, I suggested that the teacher started to deal with the everyday life in the classroom. And she did it, we went to a bar together, and I learned how to order a dish. We went to a supermarket and learned how to ask questions in a supermarket - if you don't do it you see "lb" and order "libers" instead of "pounds" (laughter) - I used to do it all the time!

Joana was also able to detect this progress in survival situations during her stay in Canada but emphasized the difficulty she still had with listening comprehension:

J: On the other hand, I have been able to "survive", for example, if I go to the bank. When I opened my account, I asked to talk to a French-speaking manager, because I wanted someone who spoke French. I was not 
going to deal with money issues without a full understanding of what was going on. But now I don't need it anymore. When I go there and want to withdraw a bigger amount from my account, or anything else, I am able to say exactly what I want. The problem is when the person starts to speak, I can't understand what the person is saying. But, overall, I have been going there and saying what I want to say.

\section{Definitions of Learning Failures}

Table 8 depicts what participants defined as learning failures and examples of situations they believed were indicators of their learning failures. These items have also been classified according to Veroff's (1977) categories:

Table 8 - What participants mean by learning failure

\begin{tabular}{|c|c|c|}
\hline PARTICIPANTS & $\begin{array}{c}\text { DEFINITIONS OF LEARNING } \\
\text { FAILURE }\end{array}$ & EXAMPLES OF LEARNING FAILURES \\
\hline Sandra & Inability to communicate $(\mathrm{T})$ & $\begin{array}{l}\text { Has to resort to dictionary frequently }(\mathrm{T}) \\
\text { In a role play activity, could not think fast and } \\
\text { express her opinion (T) } \\
\text { Has difficulty in understanding songs }(\mathrm{T})\end{array}$ \\
\hline Laura & $\begin{array}{l}\text { Perform poorly in tests and classroom } \\
\text { activities (P) }\end{array}$ & $\begin{array}{l}\text { Her mind "goes blank" when teacher asks } \\
\text { questions that require elaborate responses }(\mathrm{T})\end{array}$ \\
\hline Eduardo & $\begin{array}{l}\text { Difficulty in expressing yourself and } \\
\text { understanding what other people say (T) } \\
\text { Translating in your mind every word of a } \\
\text { text from English to Portuguese (fail to } \\
\text { "think in English") (P) }\end{array}$ & $\begin{array}{l}\text { In the beginning of his English instruction, he } \\
\text { had to translate everything from English to } \\
\text { Portuguese }(\mathrm{P})\end{array}$ \\
\hline Gabriel & Inability to understand $(\mathrm{T})$ & $\begin{array}{l}\text { Unsuccessful conversation with American } \\
\text { visitor }(\mathrm{T})\end{array}$ \\
\hline Douglas & $\begin{array}{l}\text { Feeling "impaired" in the possibility of } \\
\text { communication }(\mathrm{T})\end{array}$ & $\begin{array}{l}\text { Struggled really hard to speak and understand } \\
\text { when arrived in Canada }(T) \\
\text { Wrote a petition that had to be almost entirely } \\
\text { edited by a native speaker colleague (T) }\end{array}$ \\
\hline Joana & $\begin{array}{l}\text { Inability to perform simple everyday tasks } \\
\text { in English (T) }\end{array}$ & $\begin{array}{l}\text { Was unable to understand questions at } \\
\text { supermarket check-out }(\mathrm{T}) \\
\text { Was unable to understand answers to questions } \\
\text { she asked (T) } \\
\text { Felt scared at the possibility of questions when } \\
\text { presented a paper at a conference in English (S) }\end{array}$ \\
\hline
\end{tabular}


The definitions and situations involving learning failures were for the most part counterpoints to participants' definitions and examples of learning success: ability vs. inability to communicate, good vs. bad performance in tests and classroom activities, good vs. bad listening comprehension, ability vs. inability to survive in practical situations outside the classroom. Once again, task standards seem to prevail in determining participants' perceptions. Williams and Burden (1997) emphasize the importance of tasks and defend that it is necessary to begin with simple and controllable tasks and after some time employ more complex tasks. These tasks should allow learners to choose their own strategies to achieve their goals and to assess their own level of success (Williams and Burden, 1997). For the participants in this study, tasks where communication skills are involved seem to play a critical role in determining their sense of progress, especially the ability to express themselves in oral and written English as well as listening comprehension.

\section{Attributions and Locus of Control}

In the previous section, participants' notions and examples of learning successes and learning failures in English were presented and discussed. The present section presents attributions participants pointed out for their perceived learning successes and failures.

As indicated in Chapter Two, the notion of locus of control created by Rotter (1954) has the shortcoming of confusing locus (external $\mathrm{X}$ internal) and controllability (controllable $\mathrm{X}$ uncontrollable). Weiner (1986) criticizes this notion by arguing that locus and control are two separate elements that need to be split into two attributional dimensions: locus (external vs. internal) and controllability (controllable vs. uncontrollable). Under this perspective, the construct locus of 
control may be fragmented in order to originate two attributional dimensions. Since the researcher decided to adopt this standpoint for the study, attributions and locus of control will be treated in the same subsection.

Similarly to the previous subsection, this subsection will be divided in two further subsections that address, respectively, participants' attributions for their learning successes and learning failures. In addition, this subsection presents participants' classification of these attributions according to the criteria of locus, controllability and stability as postulated by Weiner (1986). Participants were asked about the causes that, in their view, determine their English learning successes and failures; and if they perceived these causes as internal or external to them, stable or unstable, controllable or uncontrollable.

\section{Attributions for Learning Successes}

Table 9 shows participants' attributions for doing well in English. It is important to point out that the terms for attributions below (such as effort) have been employed in previous research studies on attributions in L2 learning (Williams and Burden, 1999; Williams, Burden and Al-Baharna, 2001; Williams, Burden, Poulet and Maun, 2004) and they represent umbrella terms for participants' words. This means that not all participants, for instance, used the term "effort" in their answers but they used words that could fall into the category "effort". A similar phenomenon occurred for the classification categories: not all participants perceived loci, stability and controllability the same way. It is important, therefore, to elucidate what the participants meant by the terms presented in the table below. 
Table 9 - Participants' attributions for doing well in English

\begin{tabular}{|c|c|c|c|c|}
\hline PARTICIPANTS & $\begin{array}{l}\text { ATTRIBUTIONS } \\
\text { FOR SUCCESS }\end{array}$ & LOCUS & STABILITY & CONTROLLABILITY \\
\hline Sandra & Effort & Internal & Unstable & Controllable \\
\hline Laura & $\begin{array}{l}\text { 1. Opportunity to } \\
\text { take English } \\
\text { course } \\
\text { 2. Effort }\end{array}$ & $\begin{array}{l}\text { 1. External } \\
\text { 2. Internal }\end{array}$ & $\begin{array}{l}\text { 1. Unstable } \\
\text { 2. Unstable }\end{array}$ & $\begin{array}{l}\text { 1. Uncontrollable } \\
\text { 2. Controllable }\end{array}$ \\
\hline Eduardo & $\begin{array}{l}\text { 1. Effort } \\
\text { 2. Teacher }\end{array}$ & $\begin{array}{l}\text { 1. Can be } \\
\text { internal or } \\
\text { external } \\
\text { 2. External }\end{array}$ & $\begin{array}{l}\text { 1. Unstable } \\
\text { 2. Stable }\end{array}$ & $\begin{array}{l}\text { 1. Controllable } \\
\text { 2. Uncontrollable }\end{array}$ \\
\hline Gabriel & $\begin{array}{l}\text { 1. Effort } \\
\text { 2. Physical and } \\
\text { psychological } \\
\text { condition } \\
\text { 3. Opportunity to } \\
\text { take English } \\
\text { courses } \\
\text { 4. Access to } \\
\text { media in English }\end{array}$ & $\begin{array}{l}\text { 1. Internal } \\
\text { 2. Internal } \\
\text { 3. External } \\
\text { 4. External }\end{array}$ & $\begin{array}{l}\text { 1. Unstable } \\
\text { 2. Unstable } \\
\text { 3. Unstable } \\
\text { 4. Unstable }\end{array}$ & $\begin{array}{l}\text { 1. Controllable } \\
\text { 2. Uncontrollable } \\
\text { 3. Uncontrollable } \\
\text { 4. Uncontrollable }\end{array}$ \\
\hline Douglas & $\begin{array}{l}\text { 1. Immersion in } \\
\text { English } \\
\text { 2. Effort }\end{array}$ & $\begin{array}{l}\text { 1. External } \\
\text { 2. Internal }\end{array}$ & $\begin{array}{l}\text { 1. Unstable } \\
\text { 2. Unstable }\end{array}$ & $\begin{array}{l}\text { 1. Uncontrollable } \\
\text { 2. Controllable }\end{array}$ \\
\hline Joana & $\begin{array}{l}\text { 1. Immersion in } \\
\text { English }\end{array}$ & $\begin{array}{l}\text { Partly } \\
\text { internal, } \\
\text { partly } \\
\text { external }\end{array}$ & Unstable & Uncontrollable \\
\hline
\end{tabular}

The attribution effort was mentioned by all participants (except Joana), and it was worded in several different ways: dedication, willpower, hard work, amount of studying time, paying attention in class, doing the homework, participating in class, studying, doing the activities that are proposed inside and outside the classroom, commitment, determination, taking as many English courses as possible, using every opportunity possible, and trying to speak English in the streets and at the workplace. All the participants classified effort as internal to them. The exception for this classification is Eduardo, who classified effort as both internal and external to him. When asked for 
justification for his classification, he reported that he regards oral participation in the classroom as the main determinant of learning success in English, and according to him the factors that foster this participation can be internal or external. He has not classified effort per se but the factors that may encourage effort:

E: I believe that what determines success or failure in learning English is the person's dedication by doing the homework and mainly through participation in the classroom. Since it is only possible for us to practice our English in the classroom, the more we take advantage of the classes to speak and have our mistakes corrected, the better. I believe these causes are internal because they depend on whether the person is more outgoing or shy, but they are also external because if the classroom is a friendly environment the person will feel more comfortable to speak and participate.

Effort was also classified by all participants in this study as unstable. The major factor that seems to destabilize these participants' effort is time availability. All of them (except Gabriel) mentioned time availability as a factor that may interfere in amount of effort they invest in learning English, such as Douglas:

D: I should have more time for studying English and reading what I write down or learn in the 5 classes I have every week. But it is a matter of option (at this moment): either I develop my project or study English.

Another aspect raised by one of the participants (Laura) is the fact that students' effort to learn may suffer variations over the course of their English instruction history due to several causes. 
It seems that these causes affect students' motivation that, in turn, affects their decision to put effort in the learning enterprise:

L: Even a student that has always dedicated to learning English may be discouraged by several reasons such as doing poorly in an important evaluation (written or oral), or having to quit the English course and not feeling stimulated to study by himself (and that is the moment most students forget what they have learned and after a while they no longer want to go back to studying English).

With regard to the controllability dimension, effort was classified by all participants as controllable. They tended to establish a strong correlation between controllability and locus. This means that they regarded effort as controllable because they also viewed it as internal to them, such as Sandra:

S: Doing well in English is not totally possible to control. There are points that concern only my own self and others don't. The ones that concern my own self are under my control. However, the others aren't.

The attribution ability was not mentioned by any participants at this stage of the investigation. As stated by Covington (1998), individuals have differing opinions on ability and whether they consider effort as generating ability or as balancing for low ability (Covington, 1998). He also claims that low levels of effort may indicate a reluctance to accept responsibility for one's own lack of success, or a sense of mystification as how to improve one's language learning. This does not seem to be the case of the participants in this study. 
Two other attributions for learning success mentioned by participants were opportunity to take English courses and immersion. The first was mentioned by two EFL participants and the latter by the two ESL participants. Opportunity to take English courses was classified by these participants as external, unstable and uncontrollable, such as Laura:

L: The opportunity is out of control because we cannot always afford English courses and sometimes English is a neglected subject in regular schools.

The statement above reflects the current reality of EFL teaching in Brazil where the commonly ineffective English instruction at regular schools forces students to resort to private commercial language institutes in order to achieve higher proficiency levels in English. However, not everybody has access to these private language courses due to financial restrictions and therefore effective English instruction in Brazil is still a privilege of few people (Bohn, 2003).

Immersion in English was pointed by the two ESL participants as fundamental to learning success. It is likely that EFL students did not mention this attribution due to the fact that they had never lived a language learning experience in a foreign country. Furthermore, the ESL participants emphasized that contact with other languages (including their mother tongue) should be avoided if one wants to fully benefit from the immersion experience, such as Douglas:

D: My success now depends on immersion, without the option of speaking another language. Success in learning English is directly proportional to the time you spend thinking and trying to speak English and 
inversely proportional to the time you spend speaking your mother tongue (the less chances you have to speak Portuguese, the faster you will learn).

Attributions for Learning Failures

Table 10 shows participants' attributions for learning failures and their classification. The terms and classification categories employed below are the same as the ones used in the analysis of attributions for learning success presented above. 
Table 10 - Participants' attributions for doing poorly in English

\begin{tabular}{|c|c|c|c|c|}
\hline PARTICIPANTS & $\begin{array}{c}\text { ATTRIBUTIONS } \\
\text { FOR FAILURE }\end{array}$ & LOCUS & STABILITY & CONTROLLABILITY \\
\hline Sandra & $\begin{array}{l}\text { 1. Interruption in } \\
\text { English studies } \\
\text { 2. Lack of interest } \\
\text { 3. Ineffective } \\
\text { instruction }\end{array}$ & $\begin{array}{l}\text { 1. External } \\
\text { 2. Internal } \\
\text { 3. External }\end{array}$ & $\begin{array}{l}\text { 1. Unstable } \\
\text { 2. Unstable } \\
\text { 3. Unstable }\end{array}$ & $\begin{array}{l}\text { 1. Uncontrollable } \\
\text { 2. Controllable } \\
\text { 3. Uncontrollable }\end{array}$ \\
\hline Laura & $\begin{array}{l}\text { 1. Interruption in } \\
\text { English studies } \\
\text { 2. Shyness } \\
\text { 3. Lack of } \\
\text { opportunities to } \\
\text { practice }\end{array}$ & $\begin{array}{l}\text { 1. External } \\
\text { 2. Internal } \\
\text { 3. External }\end{array}$ & $\begin{array}{l}\text { 1. Unstable } \\
\text { 2. Unstable } \\
\text { 3. Stable }\end{array}$ & $\begin{array}{l}\text { 1. Uncontrollable } \\
\text { 2. Uncontrollable } \\
\text { 3. Uncontrollable }\end{array}$ \\
\hline Eduardo & $\begin{array}{l}\text { 1. Lack of } \\
\text { opportunities to } \\
\text { practice }\end{array}$ & 1. External & 1. Stable & 1. Uncontrollable \\
\hline Gabriel & $\begin{array}{l}\text { 1. Laziness } \\
\text { 2. Lack of } \\
\text { attention }\end{array}$ & $\begin{array}{l}\text { 1. Internal } \\
\text { 2. Internal }\end{array}$ & $\begin{array}{l}\text { 1. Unstable } \\
\text { 2. Unstable }\end{array}$ & $\begin{array}{l}\text { 1. Controllable } \\
\text { 2. Controllable }\end{array}$ \\
\hline Douglas & $\begin{array}{l}\text { 1. L1 interference } \\
\text { 2. Ineffective } \\
\text { instruction } \\
\text { 3. Lack of time } \\
\text { 4. Age } \\
\text { 5. Fatigue }\end{array}$ & $\begin{array}{l}\text { 1. External } \\
\text { 2. External } \\
\text { 3. Internal } \\
\text { 4. Internal } \\
\text { 5. Internal }\end{array}$ & $\begin{array}{l}\text { 1. Unstable } \\
\text { 2. Unstable } \\
\text { 3. Unstable } \\
\text { 4. Stable } \\
\text { 5. Unstable }\end{array}$ & $\begin{array}{l}\text { 1. Controllable } \\
\text { 2. Uncontrollable } \\
\text { 3. Uncontrollable } \\
\text { 4. Uncontrollable } \\
\text { 5. Uncontrollable }\end{array}$ \\
\hline Joana & $\begin{array}{l}\text { 1. Ineffective } \\
\text { instruction } \\
2 . \text { Emotional } \\
\text { issues } \\
\end{array}$ & $\begin{array}{l}\text { 1. External } \\
\text { 2. Internal }\end{array}$ & $\begin{array}{l}\text { 1. Unstable } \\
\text { 2. Stable }\end{array}$ & $\begin{array}{l}\text { 1. Uncontrollable } \\
\text { 2. Uncontrollable }\end{array}$ \\
\hline
\end{tabular}

Most attributions for learning failures were classified by participants as uncontrollable. One attribution raised by participants for doing poorly in English was interruption in English studies. These participants reported that they had to interrupt their English studies at some point over the course of their English instruction. They felt that this interruption contributed to the "loss" of the 
English they had learned. This attribution was classified by participants as external, unstable and uncontrollable. They explained that they viewed it as external and uncontrollable because they were forced to stop by circumstances such as lack of time and unavailability of course times that fit their schedules. They considered it unstable due to the possibility of resuming their English instruction. All the participants (except Gabriel) reported they had a "gap" or several "gaps" in their English instruction and two of them (Sandra and Laura) perceived this gap as an attribution for learning failure:

S: I believe that, for the amount of studying I did I should be in a higher level, I think. Because I studied for a long time. I almost graduated from the English course, but I should consider the fact that I had to stop for a while.

With regard to the ESL participants, they reported that they had several "gaps" in their English instruction that was, therefore, marked by several "stops" and "start attempts". Although they did not mention these gaps as an attribution for their learning failures, they also viewed it as a negative element in their learning, such as Joana:

J: Sometimes we would form a group and say "oh, we need English, so let's form a group to learn reading, to learn to read instrumental English, and so on". I had a lot of experiences like that, and sometimes I would ask my niece who was an English teacher to teach the classes, sometimes it would be a student of mine... it was always like that, without any methodology, and it was my fault, because I started, I quit, I started, I quit, and afterwards I decided to give up. 
Lack of opportunities to practice was an attribution mentioned by two EFL students (Laura and Eduardo) and it was seen as a constraint to their development in English. In the researcher's experience as an EFL teacher in Brazil, this was a typical student complaint, such as Eduardo's:

E: I think that is why it is so difficult for us to learn English, because although we read a lot and listen a lot, we don't have opportunities to talk to people, because we are in Brazil, and people choose to talk in Portuguese.

The attribution for failure that prevailed among the participants in this study was ineffective language instruction, and it was classified as external, unstable and uncontrollable. It is important to clarify what the participants meant by ineffective language instruction. To Sandra, it was associated with expectations that were not met by an English reading course she took while she was in college. She imagined that the course would be directed to her specific field (Statistics) but, due to the interdisciplinary nature of the course and the presence of classmates from several different fields, it was impossible for the teacher to carry out the activities the way she had hoped for.

Douglas reported that he took several formal English private courses in Brazil and arrived at the conclusion that they all resulted ineffective. Consequently, he developed strong resistance to those courses and this resistance constituted one of the reasons for his decision to come to Canada to learn English:

D: I think formal courses are not problem-based and they teach you an English that is not the "street English". They teach you a very formal English, and they don't enable you for the everyday life. When I arrived in Canada, with a certain English language background, and they speak to you in a contracted English using for the most part phrasal verbs and this kind of thing, you are simply ignorant in relation to what they say. When 
you try to get your message across in a slow and non contracted way, then you realize that they also do not understand what you are saying.

The ineffectiveness of EFL instruction in regular schools in Brazil (mentioned above) also applies to several Brazilian private commercial language schools (such as the ones where Douglas studied). This problem contributes significantly to EFL students' frustration with their learning. As pointed out in Douglas' statement, most private language schools fail to prepare students to use English in "real-life" situations. For the most part, these schools adopt a textbook as the syllabus and the majority of these textbooks do not expose students to practical everyday English. This constitutes a significant challenge for EFL teachers who cannot count on the immersion component to help their students achieve satisfactory proficiency levels.

Joana (the other ESL participant) presented a different perspective on ineffectiveness of the language instruction (which she also pinpointed as an attribution for her learning failures). According to her, negative experiences she had in previous English courses were responsible for an emotional block she seems to have developed to learn foreign languages and English in particular. This emotional component will be dealt with more thoroughly in a later subsection of this study.

Another attribution that emerged from participants' accounts was the age factor. Although Douglas was the only participant who regarded his "advanced age" as an attribution for failure, all the other participants stated (directly or indirectly) that the earlier one starts learning a language, the more successful the learning will render. Douglas seemed to be convinced that age played a critical role in his difficulty to learn English. He came to Canada with his wife and teenage son who, according to him, "picked up English very fast and was already fluent after 6 months", while he 
struggled to communicate in English and did not consider himself fluent in English. He mentioned the age factor several times in his interviews and reflections. A few weeks into the data collection stage of this study, the researcher had a casual encounter with Douglas and his son and was introduced to his son with the following words:

D: This is Juliana. She is doing research on why old people cannot learn English (laughter).

The discussion above is an indication that attributions may be closely associated with learners' beliefs about language learning (Woods, 1996). Joana also pointed out one of her beliefs, which is associated with one of her attributions for learning failure. She depicts this belief as a "vicious circle" that prevents her from developing listening and pronunciation skills:

J: People who have a musical ear learn languages more easily because they can repeat like parrots, without worrying about the meaning of words as I do. I need to decode words to be able to repeat them. Also, I can't hear because I don't speak well and my pronunciation is very bad, and I can't pronounce because I can't hear.

Other attributions for learning failure (mentioned by Gabriel) were laziness and lack of attention. Laziness was a recurrent attribution in Gabriel's interviews and reflections. The researcher perceived it to be a result of motivation loss over the course of his English learning history:

G: I feel a bigger resistance to English due to the fact that I have been studying it for a long time. I also believe that with time, we stay in school and the laziness increases, and therefore you do less homework, and do not progress too much. 
As a final point for this subsection, it seems evident that the range of participants' attributions for learning success and failure is considerably wide. Furthermore, these attributions may be differently classified by different people, as Weiner (1986) acknowledged in a later version of his attributional theory.

The ways learners view these attributions may determine the grounds for future action in terms of persistence, investment of more time and effort, and resolutions. For this reason, investigation on attributions and attributional classifications is of fundamental importance. Tse (2000) draws attention to the fact that "attributions of success and failure and the level of success students want to attain may determine the popularity of intermediate and upper division FL courses; and in concrete terms, attributions of success and failure in FL classrooms has implications for student decisions whether to continue language study" (Tse, 2000, p. 73).

\section{Learning Goals}

This subsection addresses the potential influence of participants' learning goals on the development of their sense of progress. As Bandura (1997) maintains, the difference between desired and obtained performance is crucial for a personal evaluation of success (Bandura, 1997). Under this perspective, desired performance is defined the goals learners set for themselves, and these goals constitute personal standards against which learners may judge their progress.

Similarly to the aspects treated in the subsections above, learners' goals were also targeted both by interview and reflection questions. In the first interview, participants were asked about their general learning goals. In one of the reflections, they were asked to pinpoint their short-term and 
long-term learning goals. For organization purposes, this subsection will be divided into two further subsections that address, respectively, participants' general learning goals and participants' proximal and distal goals.

\section{General Goals}

Table 11 displays participants' general learning goals, their perceptions about goal achieving, and their overall satisfaction with their learning progress. As mentioned above, the data for the analysis below was obtained in the first interview conducted with the participants:

Table 11 - Participants' general learning goals

\begin{tabular}{|c|c|c|c|}
\hline PARTICIPANTS & GOALS & $\begin{array}{l}\text { PERCEPTIONS ABOUT } \\
\text { GOAL ACHIEVING }\end{array}$ & $\begin{array}{l}\text { OVERALL } \\
\text { SATISFACTION WITH } \\
\text { PROGRESS }\end{array}$ \\
\hline Sandra & $\begin{array}{l}\text { PhD overseas } \\
\text { Proficiency tests }\end{array}$ & Positive & Could be better \\
\hline Laura & $\begin{array}{l}\text { Revision of items she has } \\
\text { forgotten } \\
\text { Write articles in English } \\
\text { Likes English and thinks she is } \\
\text { going to need it }\end{array}$ & Positive & "Lost" a little of her English \\
\hline Eduardo & $\begin{array}{l}\text { Travel } \\
\text { Graduate studies }\end{array}$ & Positive & Satisfied \\
\hline Gabriel & $\begin{array}{l}\text { Visit other countries } \\
\text { Study abroad }\end{array}$ & Goals are too distant & Satisfied (good grades) \\
\hline Douglas & $\begin{array}{l}\text { Write articles in English } \\
\text { Survive in English }\end{array}$ & Slower than he would like & Slow \\
\hline Joana & $\begin{array}{l}\text { No pretension of mastering } \\
\text { English due to her age } \\
\text { Find herself around } \\
\text { Understand a little more } \\
\text { Exchange ideas with people in } \\
\text { conferences }\end{array}$ & $\begin{array}{l}\text { Better if were exposed to } \\
\text { English only }\end{array}$ & $\begin{array}{l}\text { Below expectations (not } \\
\text { very satisfied) }\end{array}$ \\
\hline
\end{tabular}


None of the participants' reported learning goals represented above display an integrative character, as defined by Gardner's (1985) conception of integrative motivation. They all viewed English as a tool that will help them advance in their academic and professional careers; and allow them to communicate in foreign countries.

In addition, mastery goals seem to prevail among the participants in this study (Pintrich and Schunk, 1996). In L2 learning, mastery goals are related to language proficiency (as opposed to performance goals which are usually related to grades and scores). All the participants wished to reach higher levels of proficiency in English. Sandra was the only participant who mentioned that she was studying English in order to take an examination in the future (TOEFL ${ }^{6}$ ) This examination, however, would be a step towards her professional and academic advancement, according to her interview answers. The predominance of mastery goals among participants in this study is a positive aspect positive because, as Bandura (1997) states, learning goals related to advance in the knowledge and ability are more helpful in fostering a sense of personal efficacy than goals that concentrate on level of performance accomplishment (Bandura, 1997).

Some participants displayed "higher" proficiency level goals than others. Joana, for example, set "low" proficiency goals for herself as a response to the several failed attempts to learn English and her belief in the age factor:

$\mathrm{J}$ : My goal now is not the same as before (to master English and achieve a high level of proficiency). Because of the age I find myself in, I have no pretension of mastering English, to be able to speak or deliver a lecture. My goal today is a restricted goal. I don't have a higher goal.

Test of English as a Foreign Language 
As for participants' self-assessment in terms of their general learning goals, it is necessary to clarify the meaning of the word "positive" displayed in the table above. It is an umbrella term used by the researcher to indicate that participants perceived that they were taking the right steps towards achieving their goals, and that was the case for three participants. Out of these three participants, one reported to be satisfied with his progress (Eduardo) and the other two (Sandra and Laura) believed they still had aspects about their English to work on.

Gabriel reported that his goals of visiting other countries and studying abroad are still too distant in the future and therefore he could not estimate if he was presently guided towards the achievement of his goals:

G: I think my learning goals are very far. Because I am learning English, I know how to speak reasonably well, but my goals are far beyond of what I can imagine I will be able to accomplish today.

He also mentioned that he was satisfied with his progress because he was getting good grades and a good "learning return" in the English course. In addition, he believes English is an easy language to learn. Because this participant could not rely on his learning goals to judge his learning progress, he relied on external assessment as indicators of progress (such as grades and learning performance). The researcher believes that this is probably due to his young age (15 years old). As Williams and Burden (1999) showed in a study, younger learners tend to rely predominantly on external assessment to perceive their learning progress. Gabriel's laziness (mentioned in the previous subsection) may also be a reflection of his lack of proximal goals that would probably make him more motivated to learn English. As Bandura (1997) points out, "distant 
goals are too far removed in time to serve as favorable markers of progress along the way and to be effective self-motivators" (Bandura, 1997, p. 135).

The two ESL participants (Douglas and Joana) reported they were disappointed at their progress in terms of their learning goals. They both arrived in Canada with high expectations concerning English fluency development and encountered several difficulties and obstacles on the way, such as Douglas:

D: It also depends on your ambitions. I came to Canada with the intention to become fluent and be able to write a project or an article in English. I'm going back to Brazil frustrated because I will not be able to achieve that in a year. What I might be able to do is communicate in English, understand better, building the sentences, however, in Portuguese, with the same logic, going in circles to say something simple. Maybe I was too ambitious...

Proximal and Distal Goals

As discussed in Chapter Two, proximal goals may be fundamental in developing a sense of progress in L2 learners given the fact that they serve as guide and as pillars that sustain the individual's learning efforts. Additionally, they may provide instant rewards and incentives and constitute, therefore, helpful self-motivators. Distal goals, on the other hand, may constitute complex expectations that may cause self-demoralization through high aspiration, and are potentially not very helpful in motivational terms. This section presents participants' reported shortterm and long-terms learning goals and the ways these goals contributed (or not) to the development of their perceptions about their progress. 
Participants were asked in a reflection what their short-term and long-term goals for learning English were. Table 12 displays participants' proximal and distal goals.

Table 12 - Participants' proximal and distal goals

\begin{tabular}{|l|l|l|}
\hline PARTICIPANTS & \multicolumn{1}{|c|}{ SHORT-TERM GOALS } & \multicolumn{1}{c|}{ LONG-TERM GOALS } \\
\hline Sandra & $\begin{array}{l}\text { Study English more often } \\
\text { Go back to studying English }\end{array}$ & $\begin{array}{l}\text { Obtain a diploma in the English course } \\
\text { Take proficiency tests }\end{array}$ \\
\hline Laura & $\begin{array}{l}\text { Be able to read articles and books in } \\
\text { English } \\
\text { Write better }\end{array}$ & $\begin{array}{l}\text { Get a job } \\
\text { Take courses abroad } \\
\text { Communicate with people abroad }\end{array}$ \\
\hline Eduardo & $\begin{array}{l}\text { Keep in touch with English } \\
\text { Read scientific texts } \\
\text { Understand conversations }\end{array}$ & $\begin{array}{l}\text { Maximum fluency to travel abroad and } \\
\text { perhaps pursue graduate studies abroad }\end{array}$ \\
\hline Gabriel & $\begin{array}{l}\text { Satisfy his parents } \\
\text { Memorize colloquial English to be able to } \\
\text { carry out small dialogues without too many }\end{array}$ & $\begin{array}{l}\text { Expand vocabulary } \\
\text { Not make tense mistakes } \\
\text { Express himself without using Portuguese } \\
\text { constructions } \\
\text { Improve his writing }\end{array}$ \\
\hline Joana & $\begin{array}{l}\text { Master basic English for survival situations } \\
\text { Improve pronunciation }\end{array}$ & \begin{tabular}{l} 
Doesn't have any \\
\hline
\end{tabular}
\end{tabular}

An important question that needs to be discussed at this point is whether participants' proximal goals actually fostered a sense of progress in them. In an attempt to address this question, the researcher asked participants what they were doing to achieve their short-term goals and if they believed that the things they were doing were effective to achieve these short-term goals. All participants reported to be doing something in order to achieve their short-term goals. The activities they said they were undertaking can be classified in two types. The first type was related to active studying and it involved several activities such as doing homework and exercises, going to class, looking up words in dictionaries, reading texts from textbooks, trying to get good grades, keeping a vocabulary notebook, placing post-it notes all around the house with words in English, and 
listening to tapes. The second type was related to exposure to English and it involved listening to songs, and watching movies and TV shows.

As a whole, participants' learning activities seemed to be compatible with their reported short-term goals. In addition, the participants regarded these activities as effective to reach these goals. Eduardo, for instance, reported that his short-term goals were to keep in touch with English, read scientific texts and understand conversations. He said that in order to achieve these goals he was doing exercises, reading texts from textbooks and watching American movies without subtitles. Gabriel, who said that his proximal goal is to please his parents, reported that he was going to class, doing homework and trying to get good grades in order to achieve this goal. He believed that these activities were effective because he "had not heard anything against his performance".

Joana is an exception to this apparent congruency between participants' proximal goals and learning activities. Her proximal goals were to master a basic English for practical situations and improve pronunciation. She added that, in order to achieve these goals, she was going to classes, listening to tapes and watching movies and TV shows, rather than exposing herself to practical situations she wished to be able to handle. Furthermore, the researcher observed that during her stay in Canada she avoided these situations due to anxiety and communication apprehension (these aspects will be dealt with later in the study). Nevertheless, she reported that her listening comprehension was improving. She also mentioned that she did not have any long-term goals:

J: I no longer have long-term goals because if I don't make any progress now, I will no longer study English. I intend, this week, to look for someone to teach me approximately 10 classes and work exhaustively with my 
pronunciation. I have been asking myself if it wouldn't be better if I discussed my English learning issues with a psychologist.

Joana's situation described above suggests that proximal goal attainments may help to instill a sense of progress, as long as the activities learners undertake are congruent with these goals.

It is also important to observe that, as defended by Bandura (1997), "proximal goals are not simply subordinate conveyances to valued loftier goals since they invest activities with personal significance. The satisfaction derived from advancing accomplishments operates as its own reward during the pursuit of higher-level goals" (Bandura, 1997, p.136). This perspective could be detected in Douglas' statements about his proximal learning goals:

D: What moves me is the certainly the problem, the necessity. I learned how to set one obstacle to overcome at a time, not too arid so I don't give up, and I keep on working hard.

With regard for participants' long-term goals, for the most part they involved academic or professional advancement as well as communication skills. The long-term goal of writing academic articles, for instance, was shared by Douglas, Sandra and Laura, since this is an inherent aspect of these three participants' shared goal of an academic career.

The discussion above seems to corroborate the observation that proximal learning goals are more effective in developing a sense of progress than distant learning goals. In addition, as defended by Bandura (1997), the focus on progress rather than on distal products is crucial for 
people who are convinced of their personal inefficacy and who need evidence that they are capable of high accomplishments (Bandura, 1997).

\section{Participants' Perceptions about Other Aspects Related to Sense of Progress}

In this section, two aspects related to L2 learners' sense of progress that were not introduced in Chapter Two are discussed. These aspects emerged as recurrent and significant patterns during the data analysis stage of this study. This section is divided in two subsections named after each aspect - language skills and foreign language anxiety.

\section{$\underline{\text { Language Skills }}$}

A recurrent pattern detected by the researcher during the data analysis stage of the present study was the trend among participants to assess their progress in terms of different language skills (speaking, listening, writing, reading, vocabulary and pronunciation). For the most part, they did not evaluate their English in global terms; they would rather assess each one of these skills separately. Sandra, for instance, when asked about her perception of her learning progress in English, found it difficult to view it as a whole unit:

S: When I reflected about the concrete situations I experienced I imagined at first that it was not possible to have and not to have, simultaneously, success in learning English. That would be true if the learning took place in a uniform way in terms of oral and written expression. That certainly did not happen to me. 
When asked for clarification of the statement above, she mentioned that, for her, it was possible "to have and not to have learning success at the same time":

S: To have and not to have success at the same time means doing well in writing and doing poorly in oral, or in the comprehension of some written texts. When I think, "to have success in learning English", I imagine a unique thing, either you have it or you don't, but then, when I think of these divisions, I see that I have difficulty in some areas.

In an attempt to investigate what language skills participants considered when assessing their learning progress, the researcher searched for statements in the data that involved participants' appraisal in terms of language skills. The results of this analysis are displayed in Table 13.

Table 13 - Language skills employed by participants in appraisals of learning progress

\begin{tabular}{|l|l|l|l|l|l|l|l|}
\hline PARTICJPANTS & SPEAKING & LISTENING & WRITING & READING & GRAMMAR & VOCABULARY & PRONUNCIATION \\
\hline Sandra & $\mathrm{x}$ & & $\mathrm{x}$ & $\mathrm{x}$ & & & \\
\hline Laura & $\mathrm{x}$ & $\mathrm{x}$ & $\mathrm{x}$ & $\mathrm{x}$ & & & \\
\hline Eduardo & $\mathrm{x}$ & $\mathrm{x}$ & & $\mathrm{x}$ & & & \\
\hline Gabriel & $\mathrm{x}$ & $\mathrm{x}$ & $\mathrm{x}$ & & & & \\
\hline Douglas & $\mathrm{x}$ & $\mathrm{x}$ & $\mathrm{x}$ & $\mathrm{x}$ & & $\mathrm{x}$ & \\
\hline Joana & $\mathrm{x}$ & $\mathrm{x}$ & & & & & $\mathrm{x}$ \\
\hline
\end{tabular}

The table above shows that speaking and listening seem to prevail among skills participants consider when assessing their progress. Apparently, vocabulary and pronunciation did not receive much consideration and grammar was not mentioned at any time.

In addition to pointing out skills they employed in appraisals of learning progress, all participants reported what skills they had more facility of difficulty with. Table 14 below displays 
these perceptions about language skills. Skills marked with a (F) are those which participants reported they had facility with, and skills marked with a (D) are those which participants reported they had difficulty with.

Table 14 - Participants' view on language skills

\begin{tabular}{|l|l|l|l|l|l|l|l|}
\hline PARTICIPANTS & SPEAKING & LISTENING & WRITING & READING & GRAMMAR & VOCABULARY & PRONUNCIATION \\
\hline Sandra & (D) & & (F) & (D) \& (F) & & (D) & \\
\hline Laura & (D) & (F) & (F) & (F) & & & \\
\hline Eduardo & (D) & (F) & & (F) & & & \\
\hline Gabriel & (D) & (F) & & & & & \\
\hline Douglas & (D) & (D) & (D) & (F) & & (D) phrasal verbs & \\
\hline Joana & (D) & (D) & & & & & (D) \\
\hline
\end{tabular}

It seems that speaking is the most challenging skill for the participants in this study. They attributed this difficulty to factors such as shyness, lack of vocabulary, nervousness, lack of opportunities to practice, mother tongue interference, anxiety, poor listening comprehension and difficulty in thinking fast.

With regard to listening, the EFL participants reported they had facility with listening comprehension classroom activities. In addition, and they believed that this facility was an indicator of their learning progress. The ESL participants, in turn, reported having great difficulty in listening comprehension in the everyday situations they had to face in Canada.

As for writing skills, two participants reported having facility in writing and also viewed this facility as a learning progress indicator. The reference point they employed to develop this opinion was positive feedback they received from the teacher on classroom writing assignments: 
L: I think I am doing well in English, I have been able to do the classwork and homework activities and the teacher has not made too many corrections in my writing assignments.

For Douglas, however, a real-life writing task that involved writing a request for a scholarship turned out to be an indicator of learning failure for him. He was frustrated after he submitted the text to a colleague (a native speaker of English) for revision and she had virtually to rewrite the entire text.

D: I could feel my lack of progress in that small request that I wrote and before sending it I asked a native speaker to read it and correct it. The text correction for me was a great opportunity to compare the Canadian flow of thought to my own, so, I took this experience as a lesson. I could make comparisons in order to improve in a second attempt.

Reading was a skill which most participants reported having facility with. Nevertheless, Sandra reported that she had facility only with specific types of texts. This leads to the observation that it is possible to find differences about learners' perceptions of their progress even within the same skill.

S: It is easy for me to read technical texts like articles or books on Statistics, but if I try to access the BBC website to read some news, I have a lot of difficulty to understand it. 
Vocabulary and pronunciation did not represent crucial skills for participants in this study. Nevertheless, vocabulary was a major concern for Douglas who reported to be diligent in the study of English phrasal verbs.

D: I still have a lot of difficulty and a lot of curiosity to learn the ups, ins, outs, because I think it is practical to speak like that, but I still didn't grasp the usage. They use them all the time, "line up", "dress up", and so on. They use them a lot and in order for you to feel confident and actually improve you need to use them as well, and that is something I still cannot do.

\section{Language Anxiety}

Another recurrent aspect that emerged from the data in this study is the language anxiety factor. The relevance of such discussion lies in the observation that "disappointment with one's performance can result in anxiety that gets in the way of learning" (Ehrman, 1996, p. 148). This means that L2 learners who fail to develop a positive sense of progress may develop language anxiety, which is a potential hindrance in their learning process.

As stated by Young (1991), anxiety is often related to fear of failure. At times it is specific to one kind of activity. In other situations, it is triggered by the learning circumstances (Young, 1991). This author has established a well-known definition for the construct foreign language anxiety (henceforth FLA), that is, anxiety related to foreign language learning. She defines FLA as the feeling of stress and apprehension in second language contexts (Young, 1991). All the participants in this study seemed to display a level of FLA. For some participants, this anxiety did 
not constitute a serious obstacle to their language development. Other participants, however, seemed to be severely affected by the high levels of anxiety they displayed.

A great deal of research on FLE has demonstrated that it produces negative learning experiences (Onwuegbuzie, Bailey and Daley, 1999). Research has also revealed that, although language-anxious L2 learners may study more than their low-anxious classmates, their level of achievement often does not reflect that effort (Horwitz et al., 1986; Price, 1991). In one of his studies, Gardner (1985) concluded that anxiety is one of the greatest forecasters of foreign language learning success (Gardner, 1985).

Several authors have done research on aspects characteristics associated with FLA. (Campbell and Ortiz, 1991; Foss and Reitzel, 1988; Young, 1986). Since the researcher perceived some of these aspects surfacing during the analysis of the data, they will addressed in this subsection.

The first salient aspect about FLA some participants in this study seemed to display is communication apprehension (Horwitz et al, 1986), sometimes leading to "mental blocks" (Onwuegbuzie, Bailey and Daley, 1999, p. 218), such as in Sandra's case:

Researcher - And do you worry about pronouncing words correctly when you speak in the classroom? Sandra - Yes, I do, but I seem to have a block and I have to think about what I am saying, it is just too hard.

Communication apprehension is the anxiety learners experience in interpersonal settings. Research has demonstrated that it can be associated with learning and recall of vocabulary items (MacIntyre and Gardner, 1989). Therefore, students with high levels of communication 
apprehension may present difficulties in terms of vocabulary learning and production, such as Gabriel.

Researcher - In your fifth reflection, you mentioned that you have difficulties in speaking English. Can you tell me what these difficulties are?

Gabriel - Sometimes, either for nervousness or for simply not being able to find the word we start to stutter or we simply cannot finish sentences. Not being able to find the word in English when I am speaking is one of my biggest speaking problems. Because suddenly I get nervous, I think it is also a shyness problem, and I can't speak properly.

As stated by Horwitz et al (1986), interaction in a foreign language demands a significant amount of risk-taking (Horwitz et al., 1986). MacIntyre and Gardner (1991) demonstrated that speaking is the most anxiety-related second-language skill. In addition, Young (1990) found that most L2 learners become extremely anxious when required to speak in a foreign language in front of their class, as in the case of Laura.

Laura - I still need a lot of improvement in my speaking, I am still insecure to speak and answer questions in class. About a month ago, a German girl (my sister's friend) came to my house to spend the weekend. I could understand what she said but was not confident enough to answer, it seems that the words "run away" when you need them.

The second prominent aspect regarding FLA detected in some participants was avoidance behavior (Horwitz et al, 1986) and that implies learners turning away opportunities to communicate 
in the foreign language. Such behavior may be caused by the frustration experienced by a student unable to communicate a message that leads to apprehension about future attempts to use the language, as in Joana's case.

J: I started to avoid speaking when I was in conferences. I would let other people speak English, or I would try to meet Americans and people who spoke Portuguese, I started to avoid speaking English. (...) Since I arrived in Canada l've been meaning to buy a bottle of shampoo and check if there was a specific type of shampoo. The other day I asked myself: "why didn't I just go into the hair salon and ask?". I will try. I am trying to free myself of my emotional issues with English.

As mentioned above, some learners seem to be deeply affected by anxiety whereas others do not perceive it as a serious obstruction that hampers their learning. That seemed to be the case with Douglas, who reported not to avoid language practice situations even after being challenged by frustrating communication experiences in his first months in Canada.

D: I have made use of everything that is possible, ranging from the courses the university offers to trying not feel inhibited to speak in public. I try to speak in public, because this is my personal characteristic - even if I make mistakes, I deal well with my limitations. The involuntary laughter that I sometimes get from people when I make mistakes (it is really funny anyways), that does not affect me deeply.

Negative self-talk was another anxiety factor that one of the participants seemed to display. According to MacIntyre and Gardner (1991), learners engage in negative self-talk when they start chewing over a bad performance, which influences their ability to manage information in foreign 
language situations. (MacIntyre and Gardner, 1991). In this regard, FLA acts as an affective filter that results in the student being unreceptive to language input. (Krashen, 1980). This seemed to be Joana's case:

Joana - We were doing an activity in class and I said to a Japanese classmate: "My English is very bad". My other classmate said: Stop it! Don't say that! I think she is trying to help me overcome my tension because I keep on reinforcing how bad my English is. She says that I "write" this script for myself and therefore I cannot get out of it.

Fear of evaluation (Horwitz et al., 1986) was the last factor related to FLA that emerged during the data analysis. Several researchers have argued that heavy ego-involvement in language learning tends to increase anxiety levels (Price, 1991; Young, 1990). This observation helps to explain why students with high levels of language anxiety tend to be more afraid of negative evaluation than their low-anxious counterparts. Joana seemed to be afraid of this negative evaluation since she reported she was afraid to speak English among work colleagues at the university.

Joana - I am very scared of "scratching" my image, I think it is a little bit of vanity... I am a person who thinks she has a professional image to be preserved. 


\section{Revisiting the Definition of Sense of Progress}

The analysis and discussion of the results in this chapter of the study led to an understanding of the ways participants perceive several aspects related to their sense of progress in English learning. Some of these aspects were theoretical reference points and guides for the data collection and analysis. Others were aspects that emerged as significant and recurrent during the data analysis process. As discussed in Chapter 3, theory played a dual role in this study: it constituted both a research orientation tool and a research goal (van Lier, 1988).

The perspective on theory mentioned above allows for a reformulation and expansion of the provisional definition of sense of progress presented in Chapter Two. Such reformulation should include the new elements that surfaced as significant during the data analysis process. After consideration of which of these elements should be included, the researcher produced the following second tentative definition of L2 learners' sense of progress:

L2 learners' sense of progress is a component of metacognitive knowledge that involves learners' management and assessment of the outcomes (successes or failures) of their learning activities in face of their personally established learning goals, in particular their proximal learning goals. These successes or failures are individually defined and perceived differently by different learners, and they also exhibit variations across language tasks and language skills for individual learners. These definitions and perceptions may be influenced by internal or external factors and are strongly shaped by causal attributions learners make for their learning outcomes. An internal factor may be language anxiety, and an external factor may be the learning setting. 
Sense of progress may be an important factor in promoting learners' control over their learning process and it may be a motivational influence in L2 learning.

As a final point, it is important to restate that the definition suggested above does not represent a conclusive and comprehensive account of the notion of L2 learners' sense of progress. More research is needed in order to comprehensively delineate the foundations of the construct in question. The elaboration presented above is merely a first step that, it is hoped, will be refined and expanded with future research. 


\section{Chapter 5. Implications and Conclusion}

The present study represents an initial step towards a delineation of the construct sense of progress given that the scope of this research project does not allow for the establishment of an allencompassing theory. The author acknowledges the fact that a much larger amount of theoretical elaboration and research are needed if one ventures to describe a comprehensive model of sense of progress in language learning.

L2 learners' satisfaction with their learning progress may be viewed as a crucial motivational element. A positive sense of progress may determine learners' motivation to persist in their language learning endeavors. Students may become prone to low motivation and to passivity in the face of difficulties, particularly when success appears unattainable. The present study highlights L2 learners' perceptions about aspects related to sense of progress through their opinions, statements, and accounts of situations and experiences. The findings of this study exemplify ways the concept sense of progress operates from the standpoint of the L2 learner. In addition, they also empirically corroborate the supposition that several aspects are related to the notion of sense of progress, and that the perceptions about these aspects diverge across individuals and learning settings.

The complexity of L2 learners' sense of progress and its importance in motivational terms has practical implications for both language teachers and learners. The researcher's experience as an EFL learner and teacher in the participants' home country and as a research co-participant in the study contributed to the development of this standpoint regarding the implications of the importance of language learners' perceptions about their progress. 
Teachers can acknowledge that their students' sense of progress can be influenced by factors such as learning goals, their individual definitions of learning successes and failures, attributions, language skills, and language anxiety. This acknowledgement may be useful in the identification of ways learners can be helped to become more aware of their own progress without needing continuous teacher feedback. As Feuerstein (1991) defends, an important outcome of learning how to observe one's own progress in learning is that one comes to acknowledge personal change as uninterrupted, lifelong and within one's control. Teachers can increase the importance and power of learning experiences if they promote and build up a sense of progress in their learners (Feuerstein, 1991). In order to accomplish such development, language teachers could help and encourage learners to evaluate realistically their progress and the reasons for their successes and failures. They could also foster in students the ability to self-evaluate and therefore produce autonomous learners. Moreover, teachers could help learners experience a positive sense of progress by means of active interventions regarding each aspect that was investigated in this study. In terms of general selfassessment, teachers could elicit reports on learners' perceptions of their progress in situations occurring both in class and outside the classroom. With regard to goals, teachers may encourage students to establish realistic and productive language learning goals against which learners will be able to assess their progress. Teachers could also promote the division of students' long-term goals into a series of more manageable subgoals that, once achieved, would render helpful in providing these students with a sense of achievement. With reference to individual definitions of learning successes and failures, teachers could help learners be aware of their own criteria and beliefs about language learning, particularly of beliefs that seem counterproductive and fail to cultivate a positive 
sense of progress. Because learners' definitions of successes and failures appear to be primarily based on learning tasks, teachers could draw on a variety of classroom tasks that would function as indicators of achievement for each individual student. Concerning attributions, teachers may help students pinpoint the causes for their successes and failure and become more adaptive in their attributions. In addition, they may encourage learners to adopt a more positive approach to success and failure. They could also empower learners by means of reinforcing attributions of effort and therefore encouraging learners to be in control of their learning process, instead of relinquishing this control over to external circumstances. As for language skills, teachers may pinpoint which skills are more crucial for developing a sense of progress in their learners and help them build strategies for improvement on those skills. Finally, with regard to language anxiety, teachers may assist learners in the identification of their anxiety levels and in the determining to what extend this anxiety is distorting their perceptions of their learning progress.

Learning a new language requires willingness to invest effort in reaching clearly stated goals. In order to do this, students need a facilitator who is interested in conveying to them a sense of progress and who creates the necessary situations for conveying that feeling by means of involving students in the assessment of their learning outcomes and promoting a more challenging, active and student-centered learning environment. 


\section{References}

Agar, M. (1980). The professional stranger. New York: Academic Press.

AlFallay, I. (2004). The role of some selected psychological and personality traits of the rater in the accuracy of self- and peer-assessment. System, 32, 407-425.

Allison, D. (1998). Investigating learners' course diaries as explorations of language. Language Teaching Research, 2, 1-17.

Bailey, K. \& Ochsner, R. (1983). A methodological review of the diary studies: windmill tilting or social science? In K. M. Bailey, M. H. Long \& S. Peck (Eds.), Second language acquisition studies (pp. 199-197). Rowley: Newbury House Publishers, Inc.

Bailey, P. Onwuebugzie, A., \& Daley, C. (2000). Using learners' style to predict foreign language achievement at the college level. System, 28, 115-133.

Bandura, A. (1997). Self-efficacy: The exercise of control. New York: W. H. Freeman.

Bar-Tal, D. \& Darom, E. (1979). Pupil's attributions of success and failure. Child Development, 50, 264-267.

Barkhuisen, G. (1998). Discovering learners' perceptions of ESL classroom teaching/learning activities in a South African context. TESOL Quarterly, 32(1), 85-108.

Basturkmen, H. \& Lewis, M. (2002). Learner perspectives of success in an EAP writing course. Assessing Writing, 8, 31-46.

Beebe, L. M. \& Giles, H. (1984). Accomodation theory: a discussion in terms of second language acquisition. International Journal of the Sociology of Language, 46, 5-32. 
Block, D. (1995). Social constraints on interviews. Prospect, 10, 35-48.

Block, D. (1998). Tale of a language learner. Language Teaching Research, 2, 148-176.

Block, D. (1999). Problematizing interview data: What are they evidence of? Unpublished manuscript, Institute of Education, University of London.

Block, D. (2000). Problematizing interview data: Voices in the mind's machine? TESOL Quarterly, 34(4), 757-763.

Bohn, H. (2003). The educational role and status of English in Brazil. World Englishes, 22(2), 159172.

Brindley, G. (1984). Needs analysis and objectives setting in the adult migrant education program. Sydney: NSW Adult Migrant Education Service.

Brown, J. \& Rogers, T. (2002). Doing second language research. Oxford: Oxford University Press.

Campbell, C. \& Ortiz, J. (1991). Helping students overcome foreign language anxiety: Looking at and through the diary studies. In H. Seliger \& M. H. Long (Eds.), Classroom-oriented research in second language acquisition (pp. 67-102). Rowley, MA: Newbury House.

Carroll, J. (1973). Implications of aptitude test research and psycholinguistic theory for foreign language teaching. International Journal of Psycholinguistics, 2, 5-14.

Carroll, J. (1981). Twenty-five years of research in foreign language aptitude. In K. C. Diller (Ed.), Individual differences and universals in language learning aptitude. Rowley, MA: Newbury House.

Carroll, J. \& Sapon, S. (1959). The modern languages aptitude test. San Francisco, TX: Psychological Corporation. 
Clément, R., Dornyei, Z. \& Noels, K. (1994). Motivation, self-confidence, and group cohesion in the foreign language classroom. Language Learning, 44, 417-448.

Clément, R., \& Gardner, R. (2001). Second language mastery. In H. Giles \& W. P. Robinson (Eds.), The new handbook of language and social psychology. London: Wiley.

Cortazzi, M. \& Jin, L. (1996). Culture of learning: Language classrooms in China. In H. Coleman (Ed.), Society and the language classroom (pp. 169-206). Cambridge: Cambridge University Press.

Covington, M. (1998). The will to learn: A guide for motivating young people. Cambridge: Cambridge University Press.

Crookes, G. \& Schmidt, R. (1991). Motivation: Reopening the research agenda. Language Learning, 41, 469-512.

Cumming, A. (1994). Alternatives in TESOL research: Descriptive, interpretive, and ideological orientations. TESOL Quarterly, 28(4), 673-703.

Denzin, N. K. \& Lincoln, Y. S. (Eds.) (2000). Handbook of qualitative research (second edition). Thousand Oaks, CA: Sage.

Dörnyei, Z. (1990). Conceptualizing motivation in foreign language learning. Language Learning, $40(1), 45-78$.

Dörnyei, Z. (1994). Motivation and motivating in the foreign language classroom. The Modern Language Journal, 78(3), 273-284.

Dörnyei, Z. (1994). Understanding L2 motivation: On with the challenge! The Modern Language Journal, 78, 515-525. 
Dörnyei, Z. (1996). Moving language learning motivation to a larger platform for theory and practice. In R. L. Oxford (Ed.), Language learning motivation: Pathways to the new century. (Technical Report \#11) Honolulu: University of Hawai'i, Second Language Teaching \& Curriculum Center.

Dörnyei, Z. (1998). Motivation in second and foreign language learning. Language Teaching, 78, 117-135.

Dörnyei, Z. (2003). Attitudes, orientations, and motivations in language learning: Advances in theory, research and applications. Language Learning, 53, 3-32.

Dörnyei, Z. (2005). The psychology of the language learner. New Jersey: Lawrence Erlbaum Associates.

Dörnyei, Z. \& Skehan, P. (2003). Individual differences in second language learning. In C. J. Doughty \& M. H. Long (Eds.), The handbook of second language acquisition (pp. 589-630). Oxford: Blackwell.

Ehrman, M. (1996). Understanding second language learning difficulties. Thousand Oaks, Sage.

Ehrman, M., \& Leaver, B. (2003). Cognitive styles in the service of language learning. System, 31, $391-415$.

Ellis, R. (1989). Classroom learning styles and their effect on second language acquisition: A study of two learners. System, 17, 219-262.

Feuerstein, R., Tannenbaum, A. \& Klein, P. (1991). Mediating learning experience. Tel Aviv: Freund Publishing House Ltd.

Findley, M. \& Cooper, H. (1983). Locus of control and academic achievement: A literature review. Journal of Personality and Social Psychology, 44(2), 419-427. 
Foss, K. \& Reitzel, A. (1988). A relational model for managing second language anxiety. TESOL Quarterly, 22, 437-454.

Frieze. I., Francis, W. \& Hanusa, B. (1983). Defining success in classroom settings. In J. Levine \& M. Wang (Eds.) Teacher and student perceptions: Implications for learning (pp. 3-28). Hillsdale, New Jersey: Lawrence Erlbaum Associates.

Gardner, R. (1985). Social psychology and second language learning: The role of attitudes and motivation. London: Edward Arnold.

Gardner, R. \& Lambert, W. (1959). Motivational variables in second language acquisition. Canadian Journal of Psychology, 13, 266-272.

Gardner, R. \& Lambert, W. (1972). Attitudes and motivation in second language learning. Rowley, Massachusetts: Newbury House.

Gardner, R. \& Tremblay, P. (1995). Expanding the motivation construct in language learning. The Modern Language Journal, 79(4), 505-520.

Gersten, R. \& Baker, S. (2000). What we know about effective instructional practices for Englishlanguage learners. Exceptional Children, 66(4), 454-470.

Glaser, B. \& Strauss, A. (1967). The discovery of grounded theory. New York: Aldine de Gruyter.

Graham, S. (2004). Giving up on modern foreign languages? Students' perceptions of learning French. The Modern Language Journal, 88(2), 171-190.

Grigorenko, E., Sternberg, R. \& Ehrman, M. (2000). A theory based approach to the measurement of foreign language learning ability: The canal-F theory and test. Modern Language Journal, 84(3), 390-405.

Heider, F. (1958). The psychology of interpersonal relations. New York: John Wiley \& Sons. 
Holstein, J. \& Gubrium, J. (1995). The active interview. London: Sage.

Horwitz, E. (1985). Using student beliefs about language learning and teaching in the foreign language methods course. Foreign Language Annals, 18, 333-340.

Horwitz, E. (1987). Surveying student beliefs about language learning. In A. L. Wenden \& J. Rubin (Eds.), Learner strategies in language learning (pp. 119-129). Hemel Hempstead: Prentice Hall.

Horwitz, E. (1988). The beliefs about language learning of beginning university foreign language students. Modern Language Journal, 72, 283-294.

Horwitz, E., Horwitz, M. \& Cope, J. (1986). Foreign language classroom anxiety. Modern Language Journal, 70, 125-132.

Kolb, D. (1984). Experiential learning: Experience as the source of learning and development. Englewood Cliffs, NJ: Prentice Hall.

Krashen, S. (1980). The input hypothesis. In J. E. Alatis (Ed.), Current issues in bilingual education: Georgetown University Round Table on Language and Linguistics (pp. 168-180). Washington, DC: Georgetown University Press.

Krashen, S. (1981). Second language acquisition and second language learning. Oxford: Pergamon.

Krashen, S. (1982). Principles and practice in second language acquisition. Oxford: Pergamon.

Krashen, S. (1985). The input hypothesis. New York: Longman.

Kumaravadivelu, B. (1991). Language learning tasks: Teacher intention and learner interpretation. English Language Teaching Journal, 45(2), 98-107. 
Kvale, S. (1996). Interviews: An introduction to qualitative research interviewing. Thousand Oaks: Sage.

Lazaraton, A. (2003). Evaluative criteria for qualitative research in applied linguistics: Whose criteria and whose research? The Modern Language Journal, 87(1), 1-12.

Leki, I. (2001). Hearing voices: L2 students' experiences in L2 writing courses. In: T. Silva \& P. K. Matsuda (Eds.), On second language writing (pp. 17-28). Mahwah, NJ: Lawrence Erlbaum Associates.

Locke, E. \& Latham, G. (1984). Goal setting. Englewood Cliffs, NJ: Prentice Hall.

Locke, E. \& Latham, G. (1994). Goal setting theory. In H. F. O'Neil, Jr. \& M. Drillings (Eds.), Motivation: theory and research. Hillsdale, NJ: Lawrence Erlbaum Associates.

MacIntyre, P. (1994). Toward a social psychological model of strategy use. Foreign Language Annals, 27, 185-195.

MacIntyre, P. (2002). Motivation, anxiety and emotion in second language acquisition. In P. Robinson (Ed.), Individual differences in second language acquisition (pp. 45-68). Amsterdam: John Benjamins.

MacIntyre, P., \& Gardner, R. (1989). Anxiety and second language learning: Toward a theoretical clarification. Language Learning, 39, 251-275.

MacIntyre, P., \& Gardner, R. (1991). Investigating language class anxiety using the focused essay technique. The Modern Language Journal, 75, 296-304.

Mowrer, O. (1950). Learning theory and personality dynamics. New York: Ronald Press.

Navar, P. (1997). ESL/EFL dichotomy today: language politics or pragmatics? TESOL Quarterly, 3l(1), 9-36. 
Norton, B., \& Toohey, K. (2001). Changing perspectives on good language learners. TESOL Quarterly, 35(2), 307-322.

Nunan, D. (1991). The learner-centered curriculum. Cambridge: Cambridge University Press.

O'Malley, J. \& Chamot, A. (1990). Learning strategies in second language acquisition. New York: Cambridge University Press.

Onwuegbuzie, A., Bailey, P. \& Daley, C. (1999). Factors associated with foreign language anxiety. Applied Psycholinguistics, 20, 217-239.

Oxford, R. (1990) Language learning strategies: What every teacher should know. New York: Newbury House.

Oxford, R. \& Shearin, J. (1994). Language learning motivation: Expanding the theoretical framework. The Modern Language Journal, 78(1), 12-28.

Ozek, Y. \& Williams, M. (2000). The influence of various motivational factors on foreign language learning. In S. Cornwell \& P. Robinson (Eds.) Individual differences in foreign language learning: Effects of aptitude, intelligence and motivation. Tokyo: Japanese Association for Language Teachers.

Peck, S. (1996). Language learning diaries as mirrors of students' cultural sensitivity. In K. Bailey \& D. Nunan (Eds.), Voices from the language classroom: Qualitative research in second language education (pp. 217-236). Cambridge: Cambridge University Press.

Peirce, B. (1995). Social identity, investment and language learning. TESOL Quarterly, 29, 9-31.

Pike, K. (1967). Language in relation to a unified theory of the structure of human behaviour. The Hague: Mouton. 
Pintricht, P. \& Schunk, D. (1996). Motivation in education: Theory, research and applications. Englewood Cliffs, NJ: Prentice Hall.

Preissle, J. \& LeCompte, M. (1993). Ethnography and qualitative design in educational research. Orlando: Academic Press.

Price, M. (1991). The subjective experience of foreign language anxiety: Interviews with highly anxious students. In E. K. Horwitz \& D. J. Young (Eds.), Language anxiety: From theory and research to classroom implications (pp. 101-108). Englewood Cliffs, NJ: Prentice-Hall.

Reid, J. (1998). Understanding learning styles in the second language classroom. Upper Saddle River, NJ: Prentice-Hall Regents.

Riding, R. (1991). Cognitive styles analysis. Birmingham: Learning and Training Technology.

Rivers, W. (2001). Autonomy at all costs: An ethnography of metacognitive self-assessment and self-management among experienced language learners. The Modern Language Journal, 85(2), 279-290.

Rotter, J. (1954). Social learning and clinical psychology. New York: Prentice Hall.

Salmon, P. (1988). Psychology for teachers: An alternative approach. London: Hutchinson.

Schmidt, R. (2002). Theories, evidence, and practice in foreign language teaching. Unpublished handout from paper presented at the Conference of Nordic Languages as Second and Foreign Languages, Reykjavik, Iceland.

Silverman, D. (1997). Qualitative research: Theory, method and practice. Thousand Oaks: Sage.

Skehan, P. (1989). Individual differences in second language learning. London: Edward Arnold. 
Skehan, P. (1998). A cognitive approach to language learning. Hong Kong: Oxford University Press.

Skehan, P. (2002). Theorising and updating aptitude. In P. Robinson (Ed.), Individual differences and instructed language learning (pp. 69-93). Amsterdam: John Benjamins.

Sparks, R. (1995). Examining the linguistic coding differences hypothesis to explain individual differences in foreign language learning. Annals of Dyslexia, 45, 187-214.

Stake, R. (2000). Case studies. In N. Denzin \& Y. Lincoln (Eds.), Handbook of qualitative research (pp. 435-454). Thousand Oaks: Sage.

Strauss, A. (1987). Qualitative analysis for social scientists. New York: Cambridge University Press.

Strauss, A. \& Corbin, J. (1998). Basics of qualitative research: Techniques and procedures for developing grounded theory. Thousand Oaks: Sage.

Taylor, S. \& Bogdan, R. (1998). Introduction to qualitative research methods: A guidebook and resource. New York: John Wiley \& Sons, Inc.

Tesch, R. (1990). Qualitative research: Analysis types and software tools. London: The Falmer Press.

Tse, L. (2000). Student perceptions of foreign language study: A qualitative analysis of foreign language autobiographies. The Modern Language Journal, 84(1), 69-81.

van Lier, L. (1988). The classroom and the language learner: Ethnography and second-language classroom research. New York: Longman.

Veroff, J. (1977). Process vs. impact in men's and women's achievement motivation. Psychology of Women Quarterly, l, 283-293. 
Watson-Gegeo, K. (1988). Ethnography in ESL: Defining the essentials. TESOL Quarterly, 22, 575-592.

Weiner, B. (1983). Some methodological pitfalls in attributional research. Journal of Educational Psychology, 75(4), 530-543.

Weiner. B. (1986). An attributional theory of motivation and emotion. New York: Springer-Verlag.

Weiner, B., Russell, D. \& Lerman, D. (1979). The cognition-emotion process in achievementrelated contexts. Journal of Personality and Social Psychology, 37(7), 1211-1220.

Wenden, A. (1986). What do second language learners know about their language learning? A second look at retrospective accounts. Applied Linguistics, 7(2), 186-205.

Wenden, A. (1991). Learner strategies for learner autonomy. Hemel Hempstead: Prentice Hall

Wenden, A. (1999). An introduction to Metacognitive knowledge and beliefs in language learning. System, 27, 435-441.

Williams, M. \& Burden, R. (1997). Psychology for language teachers: A social constructivist approach. Cambridge: Cambridge University Press.

Williams, M. \& Burden, R. (1999). Students' developing concepts of themselves as language learners. The Modern Language Journal, 83(2), 193-201.

Williams, M., Burden, R. \& Al-Baharna, S. (2001). Making sense of success and failure: The role of the individual in motivation theory. In Z. Dörnyei \& R. Schmidt (Eds.), Motivation and second language learning (pp. 173-186). Honolulu: University of Hawaii Press.

Williams, M., Burden, R. \& Lanvers, U. (2002). French is the language of love and stuff: Student perceptions of issues related to motivation in learning a foreign language. British Educational Research Journal, 28(2), 503-528. 
Williams, M., Burden, R., Poulet, G. \& Maun, I. (2004). Leaners' perceptions of their successes and failures in foreign language learning. Language Learning Journal, 30, 19-29.

Woods, D. (1996). Teacher cognition in language teaching: Beliefs, decision-making and classroom practice. Cambridge: Cambridge University Press.

Young, D. (1986). The relationship between anxiety and foreign language oral proficiency ratings. Foreign Language Annals, 19, 439-445.

Young, D. (1990). An investigation of students' perspectives on anxiety and speaking. Foreign Language Annals, 23, 539-553.

Young, D. (1991). Creating a low-anxiety classroom environment: What does language anxiety suggest? The Modern Language Journal, 75, 426-439. 


\section{Appendix A}

\section{First interview schedule}

- Tell me about your experience learning English so far.

- What are your goals for learning English? Do you think you are achieving your goals? Are you satisfied with your learning progress in terms of your goals?

- How well do you think you are doing in English since you started this course (better than you expected or worse than you expected)? What are the reasons for this?

- What is your current level of motivation for learning English?

- Do you ever compare your performance in English to other people's performances? Who do you compare yourself to? How do you think you are doing in English compared to those people?

- What does "making progress in English" mean to you? Do you think it is something within your control or outside your control? Why?

- What do you think you have to do to make progress in English?

- In general, how good do you think you are at learning foreign languages? 


\section{Appendix B}

\section{Stimulus materials for guided written reflections}

Write your thoughts/reflections about the following question (each question was submitted separately for each journal entry):

REFLECTION 1: What are your distant and immediate goals for learning English and what have you been doing to achieve these goals? Give examples of things you have done in the last two weeks to achieve your IMMEDIATE English learning goals. In your opinion, were these things effective in helping you achieve these immediate goals? Why (not)? Do you plan to do anything to achieve your DISTANT goals? If so, what are some of the things you are planning to do?

REFLECTION 2: How well do you think you are doing in English? Give examples of situations you lived in the past two weeks that in your opinion are indicators of your learning success. What are the reasons for these successes you obtained? In addition (if applicable), give examples of situations you lived in the past two weeks that are indicators of learning failures. What do you think are the reasons for these failures?

REFLECTION 3: How would you classify your current level of motivation to learn English? Describe any fluctuations in this level of motivation you might have experienced since you began the English course at this institution.

REFLECTION 4: In your opinion, what does it mean to do well / badly in English? Give concrete examples of English-related situations where you think you did well / badly in the last weeks/ months.

REFLECTION 5: How do you know you are doing well in English? What criteria do you use to evaluate your own learning progress (grades/feedback from the teacher/ comparison with others/ ability to read, write, listen or converse in English, etc)? Based on your own criteria, how well do you think you are doing? What are the causes for this? Based on your own criteria, what do plan to do to enhance your learning (if that is applicable)?

REFLECTION 6: Do you think doing well in English is something within your control or out of your control? What are some internal/external causes that might determine your learning successes and failures? In your opinion, are these causes stable or unstable (i.e., can they be changed or not)? Why? 


\section{Appendix C}

Analytical questions that directed the coding

\begin{tabular}{|c|c|c|c|}
\hline CATEGORIES & QUESTIONS & SUBCATEGORIES & QUESTIONS \\
\hline \multirow[t]{2}{*}{ Self-assessment } & \multirow[t]{2}{*}{$\begin{array}{l}\text { How do participants monitor and } \\
\text { evaluate the success of their } \\
\text { learning activities? }\end{array}$} & General criteria & $\begin{array}{l}\text { How do participants monitor and } \\
\text { evaluate the success of their learning } \\
\text { activities in more abstract terms? }\end{array}$ \\
\hline & & Concrete examples & $\begin{array}{l}\text { How do participants monitor and } \\
\text { evaluate the success of their learning } \\
\text { activities in more concrete terms? }\end{array}$ \\
\hline \multirow[t]{2}{*}{ Motivation } & \multirow[t]{2}{*}{$\begin{array}{l}\text { Did participants perceive sense of } \\
\text { progress as a motivational } \\
\text { antecedent? }\end{array}$} & Initial perceptions & $\begin{array}{l}\text { How satisfied are participants with } \\
\text { their learning progress and what is } \\
\text { their perceived motivational level? }\end{array}$ \\
\hline & & Later perceptions & $\begin{array}{l}\text { What situations and factors caused } \\
\text { participants' perceived motivation } \\
\text { levels to increase or decrease? } \\
\text { Which situations and factors pointed } \\
\text { out by participants are related to their } \\
\text { sense of progress in terms of } \\
\text { perceived performance, learning } \\
\text { improvement and feedback? }\end{array}$ \\
\hline \multirow[t]{2}{*}{$\begin{array}{l}\text { Definitions of success } \\
\text { and failure }\end{array}$} & \multirow{2}{*}{$\begin{array}{l}\text { What do participants mean by } \\
\text { language learning successes and } \\
\text { failures? }\end{array}$} & $\begin{array}{l}\text { Definitions of } \\
\text { success }\end{array}$ & $\begin{array}{l}\text { What do participants mean by } \\
\text { language learning successes? }\end{array}$ \\
\hline & & Definitions of failure & $\begin{array}{l}\text { What do participants mean by } \\
\text { language learning failures? }\end{array}$ \\
\hline \multirow[t]{2}{*}{$\begin{array}{l}\text { Attributions and Locus } \\
\text { of Control }\end{array}$} & \multirow[t]{2}{*}{$\begin{array}{l}\text { What causal attributions do } \\
\text { participants make for their } \\
\text { learning successes and failures } \\
\text { and how do they classify them? }\end{array}$} & $\begin{array}{l}\text { Attributions for } \\
\text { learning successes }\end{array}$ & $\begin{array}{l}\text { What causal attributions do } \\
\text { participants make for their learning } \\
\text { successes and how do they classify } \\
\text { them? }\end{array}$ \\
\hline & & $\begin{array}{l}\text { Attributions for } \\
\text { learning failures }\end{array}$ & $\begin{array}{l}\text { What causal attributions do } \\
\text { participants make for their learning } \\
\text { failures and how do they classify } \\
\text { them? }\end{array}$ \\
\hline \multirow[t]{2}{*}{ Learning goals } & \multirow[t]{2}{*}{$\begin{array}{l}\text { What are participants' learning } \\
\text { goals and how do these goals } \\
\text { contribute to foster a sense of } \\
\text { progress in these participants? }\end{array}$} & General goals & $\begin{array}{l}\text { What are participants' general } \\
\text { learning goals and how do these } \\
\text { goals contribute to foster a sense of } \\
\text { progress in these participants? }\end{array}$ \\
\hline & & $\begin{array}{l}\text { Proximal and distal } \\
\text { goals }\end{array}$ & $\begin{array}{l}\text { What are participants' proximal and } \\
\text { distal goals and how do these goals } \\
\text { contribute to foster a sense of } \\
\text { progress in these participants? }\end{array}$ \\
\hline Language skills & \multicolumn{3}{|c|}{ What language skills do participants consider when assessing their learning progress? } \\
\hline Language anxiety & \multicolumn{3}{|c|}{$\begin{array}{l}\text { What learning experiences reported by participants seem to indicate a level of language } \\
\text { anxiety? }\end{array}$} \\
\hline
\end{tabular}

